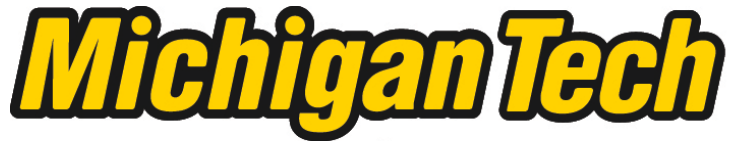 \\ Michigan Technological University Create the Future Digital Commons @ Michigan Tech
}

Dissertations, Master's Theses and Master's Reports - Open

2012

\section{STABILITY ANALYSIS AND HAZARD ASSESSMENT OF THE NORTHERN SLOPES OF SAN VICENTE VOLCANO IN CENTRAL EL SALVADOR}

Daniel Smith

Michigan Technological University

Follow this and additional works at: https://digitalcommons.mtu.edu/etds

Part of the Engineering Commons

Copyright 2012 Daniel Smith

Recommended Citation

Smith, Daniel, "STABILITY ANALYSIS AND HAZARD ASSESSMENT OF THE NORTHERN SLOPES OF SAN VICENTE VOLCANO IN CENTRAL EL SALVADOR", Master's Thesis, Michigan Technological University, 2012.

https://doi.org/10.37099/mtu.dc.etds/471

Follow this and additional works at: https://digitalcommons.mtu.edu/etds

Part of the Engineering Commons 


\title{
STABILITY ANALYSIS AND HAZARD ASSESSMENT OF THE NORTHERN SLOPES OF SAN VICENTE VOLCANO IN CENTRAL EL SALVADOR
}

\section{By}

Daniel M. Smith

\begin{abstract}
A THESIS
Submitted in partial fulfillment of the requirements for the degree of MASTER OF SCIENCE

In Geological Engineering
\end{abstract}

MICHIGAN TECHNOLOGICAL UNIVERSITY

2012

(C) 2012 Daniel M. Smith 
This thesis has been approved in partial fulfillment of the requirements for the Degree of MASTER OF SCIENCE in Geological Engineering.

Department of Geological and Mining Engineering and Sciences

Thesis Co-Advisor: $\quad$ Dr. Thomas Oommen

Thesis Co-Advisor: Dr. John Gierke

Committee Member: $\quad$ Dr. David Watkins

Committee Member: Dr. Stanley Vitton

Department Chair: Dr. Wayne Pennington 


\section{Table of Contents}

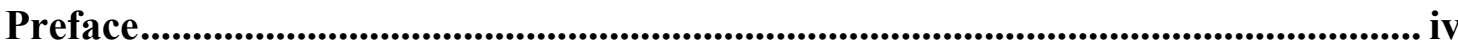

Acknowledgements .......................................................................................................... v

List of Abbreviations .................................................................................................. vi

Abstract.......................................................................................................................................... vii

$1.0 \quad$ Introduction .............................................................................................................. 1

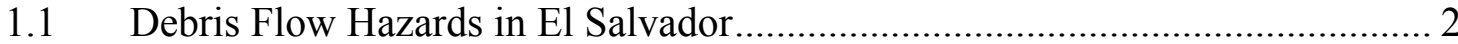

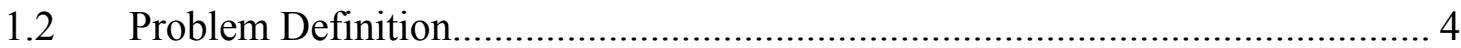

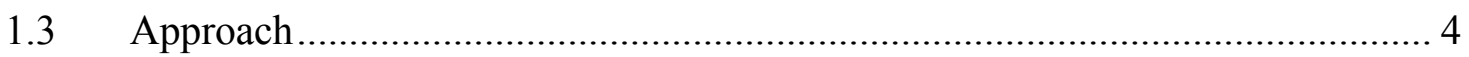

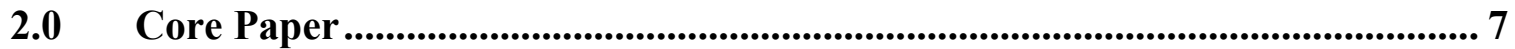

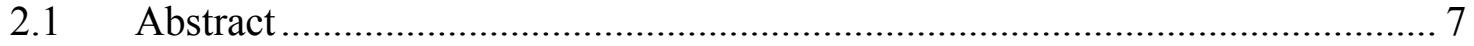

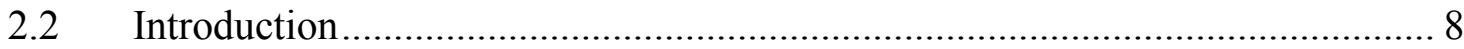

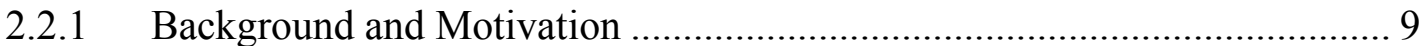

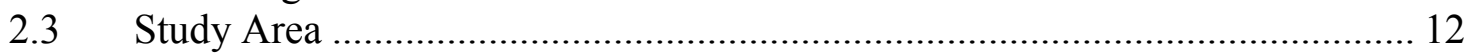

2.3.1 Geologic Characteristics and Volcanic Structure ……………………...... 12

2.3.2 Climatic Conditions ........................................................................... 14

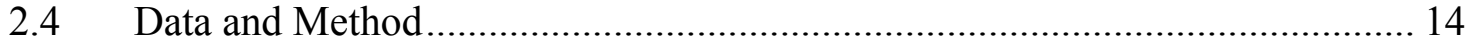

2.4.1 Field and Laboratory Work................................................................. 14

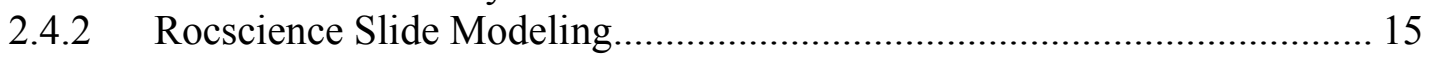

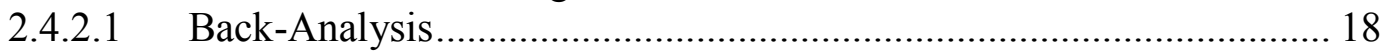

2.4.2.2 Forward Modeling …………………......................................... 23

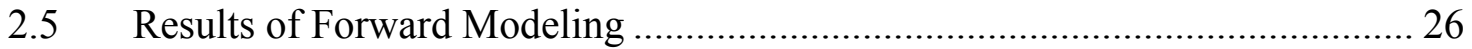

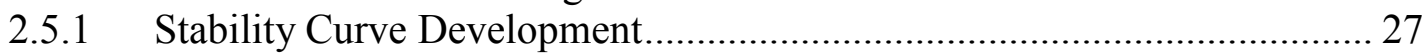

2.5.2 Potential Impact for Communities .............................................................. 32

2.5.3 Recommendations for Future Work..................................................... 32

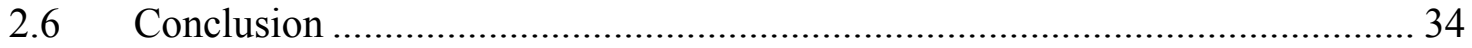

3.0 Summary ................................................................................................................ 35

4.0 References ...................................................................................................................... 37

5.0 Appendices................................................................................................................. 41

5.1 Appendix A: Field Work Report and Results of Field Tests ........................... 42

5.2 Appendix B: Grain Size Analyses .............................................................. 46

5.3 Appendix C: Supporting Calculations .......................................................... 48 


\section{Preface}

The core chapter included in this thesis, "Assessment of rainfall-induced landslides on the northern flank of San Vicente Volcano in Central El Salvador," will be submitted for publication. This paper includes several co-authors whose expertise and guidance made the paper possible. Thomas Oommen, John Gierke and Stanley Vitton all provided technical guidance for the project, and Luke Bowman was invaluable in setting up the field work and obtaining data from El Salvador. It should be noted that the majority of the paper ( $95 \%)$ was written by me and I created all of the tables and figures.

Additionally, I completed and analyzed all of the computer modeling, as well as played a major role in the field campaign. 


\section{Acknowledgements}

This research was supported by the Remote Sensing for Hazard Mitigation and Resource Protection in Pacific Latin America grant (NSF PIRE \#0530109)

I would like to thank my advisors, Dr. Thomas Oommen and Dr. John Gierke for all of their support, ideas and guidance on this project.

Additional thanks to my committee members Dr. David Watkins and Dr. Stanley Vitton

Luke Bowman was instrumental in more ways than can be recounted. Many thanks to Luke for facilitating the field campaign, as well as being an endless source of ideas and information on the project.

Furthermore, I would extend my gratitude to all of the Salvadorans who were of great assistance both in the field and while back in the USA: Professors Edgar Antonio Orantes and Jose Fredy Cruz Centeno from the University of El Salvador, Adonnay Hernandez, Rutilio Antonio Parada Galan and Javier Sorto from CEPRODE, Santiago Crespin and Fausto Moreno from San Vicente Civil Protection and to Inspector Mauricio Saade from the Policia Nacional Civil de San Vicente for providing security during field work.

Finally, no amount of thanks could suffice for Rachael. Her endless support and encouragement is inspiring. 


\section{List of Abbreviations}

$\begin{array}{ll}\text { DEM } & \text { Digital Elevation Model } \\ \text { FOS } & \text { Factor of Safety } \\ \text { GFDRR } & \text { Global Facility for Disaster Reduction and Recovery } \\ \text { GIS } & \text { Geographic Information System } \\ \text { LEM } & \text { Limit Equilibrium Method } \\ \text { NGO } & \text { Non-Governmental Organization } \\ \text { SNET } & \text { Servicio Nacional de Estudios Territoriales } \\ \text { SWCC } & \text { Soil Water Characteristic Curve } \\ \text { TBJ } & \text { Tierra Blanca Joven } \\ \text { USGS } & \text { United States Geological Survey }\end{array}$




\begin{abstract}
Geologic hazards affect the lives of millions of people worldwide every year. El Salvador is a country that is regularly affected by natural disasters, including earthquakes, volcanic eruptions and tropical storms. Additionally, rainfall-induced landslides and debris flows are a major threat to the livelihood of thousands. The San Vicente Volcano in central El Salvador has a recurring and destructive pattern of landslides and debris flows occurring on the northern slopes of the volcano. In recent memory there have been at least seven major destructive debris flows on San Vicente volcano. Despite this problem, there has been no known attempt to study the inherent stability of these volcanic slopes and to determine the thresholds of rainfall that might lead to slope instability. This thesis explores this issue and outlines a suggested method for predicting the likelihood of slope instability during intense rainfall events. The material properties obtained from a field campaign and laboratory testing were used for a 2-D slope stability analysis on a recent landslide on San Vicente volcano. This analysis confirmed that the surface materials of the volcano are highly permeable and have very low shear strength and provided insight into the groundwater table behavior during a rainstorm. The biggest factors on the stability of the slopes were found to be slope geometry, rainfall totals and initial groundwater table location. Using the results from this analysis a stability chart was created that took into account these main factors and provided an estimate of the stability of a slope in various rainfall scenarios. This chart could be used by local authorities in the event of a known extreme rainfall event to help make decisions regarding possible evacuation. Recommendations are given to improve the methodology for future application in other areas as well as in central El Salvador.
\end{abstract}




\subsection{Introduction}

Geologic hazards are a part of everyday life for millions of people worldwide. Every year major earthquakes, volcanic eruptions, landslides and other natural phenomena make the news because of the destruction they cause, and are often all too quickly forgotten. Those who live in these danger zones cannot afford to forget. They live daily with the possibility of destruction and are always aware and occasionally harshly reminded of the imminent threat that goes with living in a hazard area.

The country of El Salvador, located on the middle Pacific coast of Central America, is uniquely vulnerable to numerous natural hazards. El Salvador is both the smallest and most densely populated country in Central America. Much of the population is concentrated in a few large cities, most of which (as illustrated in Figure 1.1) are in close proximity of a major volcano. Approximately one quarter of the population living in these high-risk areas are exposed to high probabilities of death (GFDRR 2011; Major et al. 2004). The combination of the country's geological setting and socioeconomic situation leads to a potentially disastrous combination of high population densities located in and near hazardous areas (Rose et al. 2004). These unique circumstances have led to a number of studies attempting to quantify and reduce the risk to people living in harm's way.

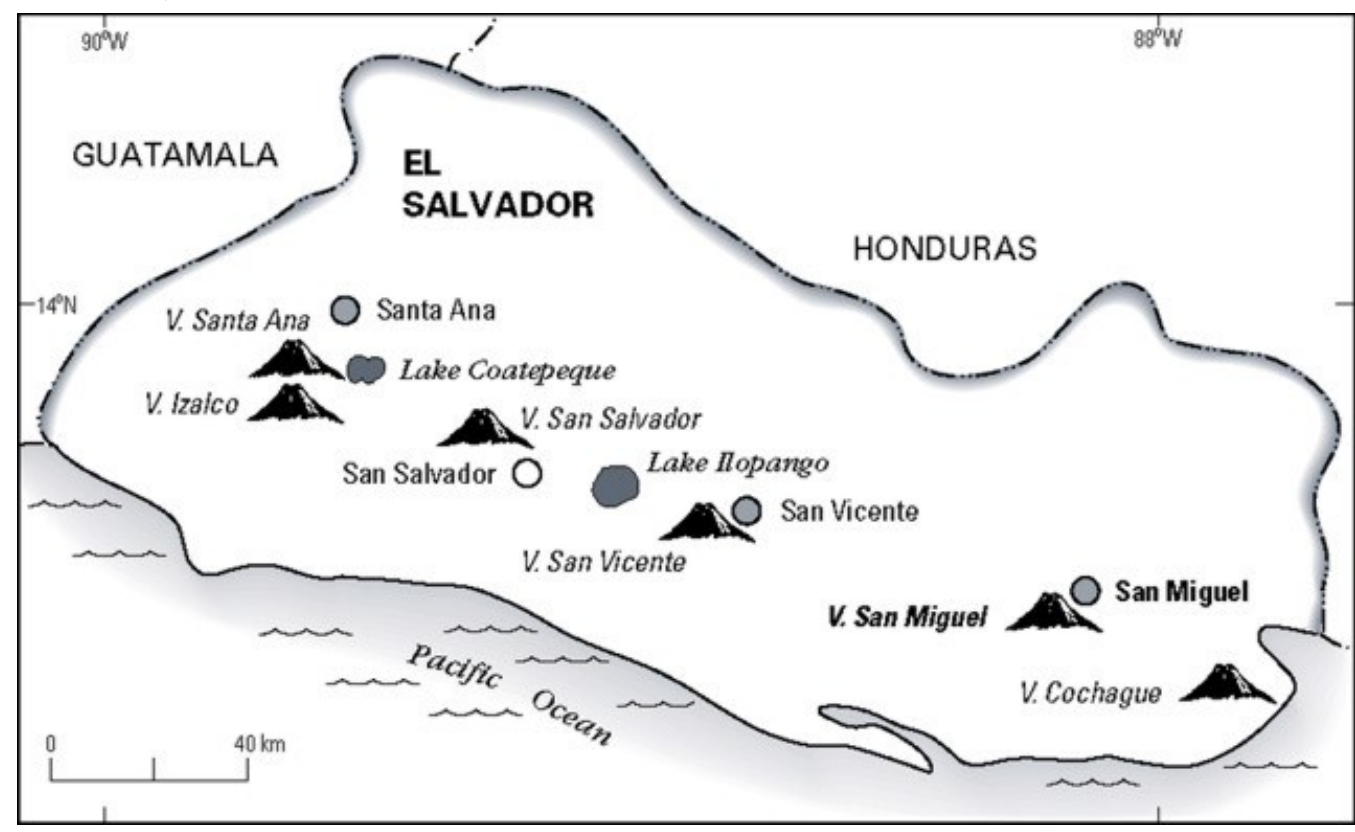

Figure 1.1: Location of major volcanoes (cones) and cities (circles) within EI Salvador. Reprinted from Major et al. (2004) 
It has been estimated that over the last 30 years, natural disaster events have cost the country of El Salvador $\$ 4.57$ billion and nearly 4,000 lives; the largest contributors to these totals have been large earthquakes and tropical storm events (GFDRR 2011). El Salvador ranks second worldwide among countries with highest economic risk from two or more disasters (Dilley et al. 2005). Events such as the 1986 and 2001 major earthquakes cost El Salvador immense amounts of both money and effort to clean up and rebuild, and had a significant economic toll on the country (total cost estimated at $\$ 3.3$ billion.) Landslides also cause significant damage in El Salvador. As noted by the Global Facility for Disaster Reduction and Recovery, recent meteorological events responsible for causing landslides in El Salvador include Hurricane Mitch in 1998 (\$400 million total damage and 240 deaths), Hurricane Stan in 2005, Hurricane Ida in 2009 (\$315 million in total damage and 200 deaths) and Hurricane Agatha in 2010 (\$112 million in total damage and 12 deaths.) The totals from these events alone (approximately $\$ 830$ million and 450 deaths) make landslides and their related hazards the second most costly hazard El Salvador faces, both in dollars and in lives.

\subsection{Debris Flow Hazards in El Salvador}

Shallow landslides caused by torrential rainfall are common in hilly tropical regions around the world (Godt et al. 2009). The Salvadoran government has identified at least 723 areas considered prone to landslides, representing almost $2 / 3$ of the country (GFDRR 2011). While there are many types of slope failures that can occur on volcanoes, and they all have the potential to cause destruction and present hazards, the mobilization of debris flows from shallow landslides is one type of failure that is of special concern in El Salvador. Debris flows, called lahars when associated with volcanos and commonly referred to "mudflows" in everyday situations, are different from landslides in that they move downslope in the fashion of a stream. These flows consist of watery mud and entrain sediment, rocks, boulders and other debris (such as trees or even infrastructure) that gets in the way. Debris flows often initiate as shallow landslides high up on a slope that are typically triggered by intense rainfall events and/or earthquakes. These shallow landslides then mobilize from a simple slump into a flow because of availability of excess water to entrain and carry sediment. Debris flows typically follow existing flow channels downslope, as would a stream, but unlike streams can contain as much as $70 \%$ solids by weight, giving them much more momentum to continue further downslope at higher speeds (Varnes 1978). The high soil content also contributes to scouring and mobilizing sediment all the way down the slopes, ensuring that the flow maintains or even increases its volume well beyond the initial failure surface. Because of this extra momentum and self-perpetuating behavior of adding material to the flow, debris flows are often capable of traveling up to tens of kilometers and at speeds up to $20 \mathrm{~m} / \mathrm{s}$ (Takahashi 1981).

Debris flows are relatively common in volcanic and hilly terrains worldwide, and often times do not affect people where they live (Godt et al. 2009). However, they become 
hazardous when they travel far enough downslope to affect communities, especially in the fertile areas surrounding volcanoes where agriculture-based communities often form. As Major (2004) points out, the hazard of debris flows is that they can travel far from the volcanic cone and out into the terrain around it, where people typically live. The biggest hazards associated with debris flows are the deposition of sediment and the destruction of buildings and infrastructure that are in the way. The events that occurred on the Casita volcano in Nicaragua in 1998 are an example of how destructive rainfall-induced debris flows can be. Intense rainfalls associated with Hurricane Mitch dumped $\sim 750 \mathrm{~mm}$ of rain over several days, causing a large slope failure on the volcano that mobilized into a huge debris flow that tore through several nearby communities and killed at least 2,500 people (Scott et al. 2005).

The problems of shallow landslides and debris flows in volcanic terrains cause numerous issues in El Salvador, especially near the major volcanoes. Major et al. (2004) reports at least 20 rainfall-initiated debris flows in recent recorded history: 2 on San Salvador Volcano, 11 on San Miguel Volcano and 7 on San Vicente. Two notable historic events on the San Vicente volcano accounted for in this total are the 1934 debris flows in the community of Tepetitán and the 2001 flows in the town of Guadalupe.

The Tepetitán flows from 1934 were believed to have been triggered by rainfall and destroyed much of the village, necessitating reconstruction in a new location that is still located on the same alluvial fan (Jibson et al. 2004). The 2001 events in Guadalupe were a rainfall-induced mobilization of material deposited by the large January and February earthquakes of that same year. These debris flows were responsible for killing at least two people, and destroyed temporary shelters and other buildings on the northeast part of town (Crone et al. 2001).

The largest and most destructive debris flows that have occurred in recent history on the San Vicente volcano are those associated with Hurricane Ida in 2009. In November 2009 Hurricane Ida passed through Central America, dumping more than $480 \mathrm{~mm}$ of rain on the upper slopes of San Vicente in less than two days, with a peak rainfall intensity of over $80 \mathrm{~mm} / \mathrm{hr}$ (Schweig et al. 2010). During the peak intensity of this storm, shallow landslides high on the volcano initiated a series of destructive debris flows during the early morning hours of November 8 . These debris flows tore through several of the communities on the northern flanks of the volcano, notably Verapaz and Guadalupe and were responsible for an estimated 200 deaths.

As previously noted, the debris flows associated with Ida caused $\$ 315$ million in damage and triggered an outpouring of support and resources to better prepare and educate the local population for another possible event. In the time since, numerous NonGovernmental Organizations (NGOs) as well as the Salvadoran Civil Protection have been holding trainings and workshops with the communities most affected in the past and at risk in the future. In addition to these trainings and support, it is necessary for the organizations and individuals making decisions during times of elevated risk to have the 
best information available to make an informed decision. This work fills in some of the gaps and will provide a tool that these individuals can use as part of the decision making process.

\subsection{Problem Definition}

The objectives of this research were threefold:

1) Back analyze the shallow landslides that occurred during Hurricane Ida to determine the critical thresholds of the various destabilizing factors (rainfall, groundwater location, etc.) that cause slope instability at San Vicente Volcano

2) Evaluate the slope instability hazard at San Vicente Volcano

3) Develop a useful tool for the Salvadoran stakeholders to determine the hazard from rainfall induced slope instability at San Vicente Volcano which in turn would help to determine the communities at risk in an emergency event

\subsection{Approach}

Commonly, slope instability and debris flow potential are analyzed with GIS in a spatial fashion, using records of past events and a few typical criteria for failure, such as slope angle, soil type, typical maximum rainfall, etc. (Gabet and Mudd 2006; Godt et al. 2008; Larsen and Simon 1993; Montgomery et al. 1998). The output of these is typically a probability based on the given variables indicating either "Yes there will likely be debris flows" or "No there will likely not be debris flows," which is a simple and effective way to know when a few key criteria are met. This approach has been widely used by the United States Geological Survey (USGS) on the Cascade volcanoes in the Pacific Northwest, as well as in other debris flow prone areas of the United States, and has been applied in developing countries like Honduras and Micronesia (Harp et al. 2009). This approach is effective when there is sufficient information available (rainfall, soil distribution and properties, inventory of past events, etc.) for the study site. However, in places like El Salvador where there is limited data availability outside of the capital city region and not enough inventory of past events, it can be difficult to create an effective GIS-based model.

A major limitation of this GIS-based approach is the fact that typically it is not used in conjunction with considering the strength properties of the soils in question, and it has been acknowledged that with sufficient information a site-specific model that takes into account more of the strength properties of the soil would prove beneficial (Godt et al. 
2008). Additionally, being empirical in nature, these models typically are not governed by the physics of transient groundwater and geotechnical slope stability analysis. This project considers these areas of potential research and approaches the issue of rainfallinduced shallow landslides and resulting debris flows from a different angle than is typically pursued. Because of the remote nature of the study area, much of the information that would be required to create an effective model using these methods is lacking. Instead of using GIS-based analysis and specific criteria to isolate what conditions would lead to a slope instability, these conditions were isolated using slope stability analysis. These conditions were subsequently applied with forward modeling to evaluate the potential hazard.

Back analyses are commonly used to isolate certain factors leading to slope instability (Collins and Znidarcic 2004; Gofar et al. 2006; Tutluoglu et al. 2011). These analyses are performed to simulate and re-create a past event using all known information. Using a slope stability modeling program (for this project Rocscience Slide 6.011; many others are commercially available,) a past failure event is modeled with all known criteria and variables and any unknown variables are identified. These variables can be strength properties of the soils in question, water table location, critical rainfall thresholds and other factors that can lead to slope failure. When the unknown factors have been constrained using this method, one can use the identified values for a forward model to simulate potential future events that have not yet occurred.

The available spatial, soil and rainfall data for the San Vicente volcano was suitable for the creation of such a model to simulate shallow landslides that would typically trigger debris flows in extreme rainfall events. A schematic of the model used can be found in Figure 1.2, and further detail on the model is given in the next chapter of this thesis. The 2-D slope stability model takes into account varied infiltration over time and calculates estimated water table fluctuations. The effects of these fluctuations and material properties are then used in determining the stability of the slope. This approach is a new and unique application of slope stability modeling and is believed to provide the best insight to the initiation of debris flow events based on available information. We hope that the development of a method for hazard analysis in this fashion will be relevant for many other locations that lack the necessary inputs for other, more sophisticated models. This research will provide a framework outlining a new method for analyzing the hazards presented by shallow rainfall-induced landslides and debris flows. 


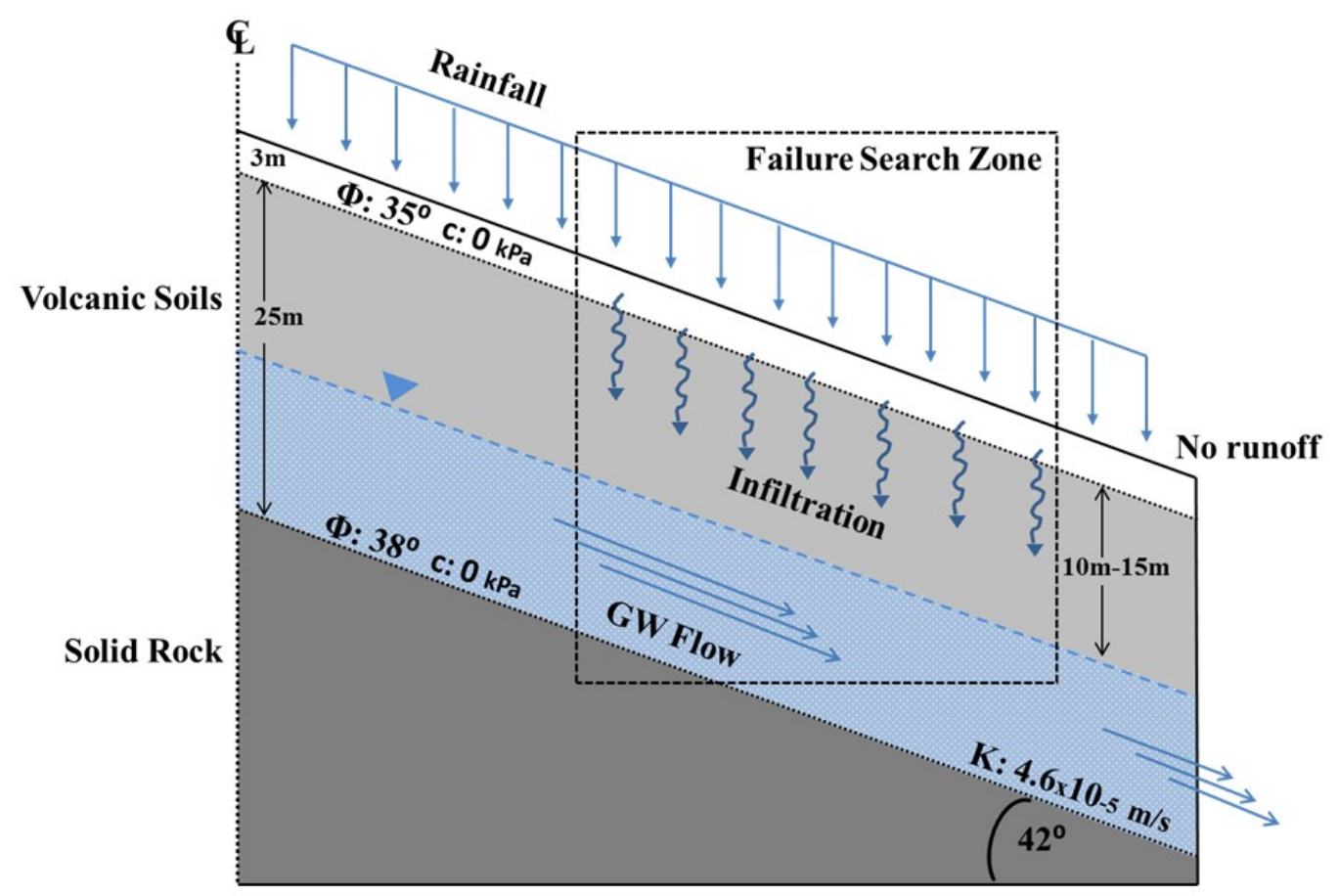

Figure 1.2: Schematic of 2-D slope stability model

The current hazard assessment for debris flows on the San Vicente volcano was provided by the USGS in the form of a general map showing potential inundation areas for debris flows of three given volumes coming from the volcano (Major et al. 2004). The volumes used in this assessment are based on likely volumes of past events and no particular attention is given to specific areas of concern or drainages that have highest potential impact on communities below. As provided and utilized concurrently with established rainfall thresholds, this is a very useful tool for planning purposes and community awareness. However, during an actual tropical storm event, it does not fully inform decision makers with enough information to make decisions about evacuating or passing information on to communities whether or not they should be worried about a slope failure during that particular event. This research seeks to address that need.

This project focuses on the development of a tool that decision makers who were a part of monitoring and reporting efforts could use during an event to evaluate the current hazard presented by a storm. This tool is based on stability modeling and transient groundwater conditions during rainfall events and can give an extra level of confidence to the decision making process during an event. Using initial water table location and cumulative rainfall totals during a rainfall, the user can predict the likelihood of a possible slope failure and factor that into evacuation decisions. The sensitivity of the base model to various factors is analyzed, and an example final stability chart is given, along with suggestions for improving the framework for future application elsewhere. 


\title{
2.0 Core Paper ${ }^{1}$
}

\section{Assessment of rainfall-induced landslides on the northern flank of San Vicente Volcano in Central El Salvador}

\author{
Daniel M. Smith, Thomas Oommen, Luke J. Bowman, John S. Gierke, Stanley J. Vitton \\ Department of Geological and Mining Engineering and Sciences, Michigan \\ Technological University, Houghton, MI, USA
}

\subsection{Abstract}

The San Vicente Volcano in central El Salvador has a recurring and destructive pattern of landslides and debris flows occurring on the northern slopes of the volcano. In recent memory, there have been at least seven major destructive debris flows on San Vicente volcano. There has been no known attempt to study the inherent stability of these volcanic slopes and to determine the thresholds of rainfall that might lead to slope instability. In this study, this issue is explored and a suggested method for predicting the likelihood of slope instability during intense rainfall events it outlined. A 2-D slope stability back-analysis was performed on a recent landslide on San Vicente volcano to estimate the unknown model parameters. This analysis confirmed that the surface materials of the volcano are highly permeable and have very low shear strength. Additionally, the analysis provided insight into the groundwater table behavior during a rainstorm. The soils in this analysis have a friction angle between $35^{\circ}$ and $38^{\circ}$, and are assumed to have no cohesive strength. The water table depth suggested by back analysis is approximately $15 \mathrm{~m}$. Slope geometry, rainfall totals and initial groundwater table location were found to have the greatest effect on stability for this analysis. A methodology is outlined for the creation of a tool that could be of use during rainfall events for monitoring slope stability. A stability chart was created that took into account the results of back analysis and provided an estimate of the stability of a slope in various rainfall scenarios. This chart could be used by local authorities in the event of a known extreme rainfall event to help make decisions regarding possible evacuation. Recommendations are given to improve the methodology for future application in other areas as well as in central El Salvador.

\footnotetext{
${ }^{1}$ The material contained in this chapter will be submitted for publication.
} 


\subsection{Introduction}

El Salvador, the smallest and most densely populated country in Central America, is a country regularly subject to major natural disasters. Estimates indicate that over the last 30 years earthquakes and tropical storms alone have cost the country of El Salvador $\$ 4.57$ billion and nearly 4,000 lives (GFDRR 2011). Its location in the tropics on the Pacific coast of Central America, along the Middle America Trench and the Pacific Ring of Fire, results in its high vulnerability to earthquake, tropical storm related hazards and volcanic activity. Of particular concern to El Salvador are rainfall-induced landslides and related debris flows in volcanic terrains associated with the four major volcanoes, Santa Ana, San Salvador, San Vicente and San Miguel, near which almost half of the country's population lives (Major et al. 2004). This combination of the geological setting and socioeconomic situation of El Salvador has led to a potent combination of high population densities located in and near hazardous areas (Rose et al. 2004). This unique situation is the motivation behind the current study, which is an attempt to define and assist in the mitigation of hazards from debris flows on the San Vicente volcano, shown in Figure 2.1.

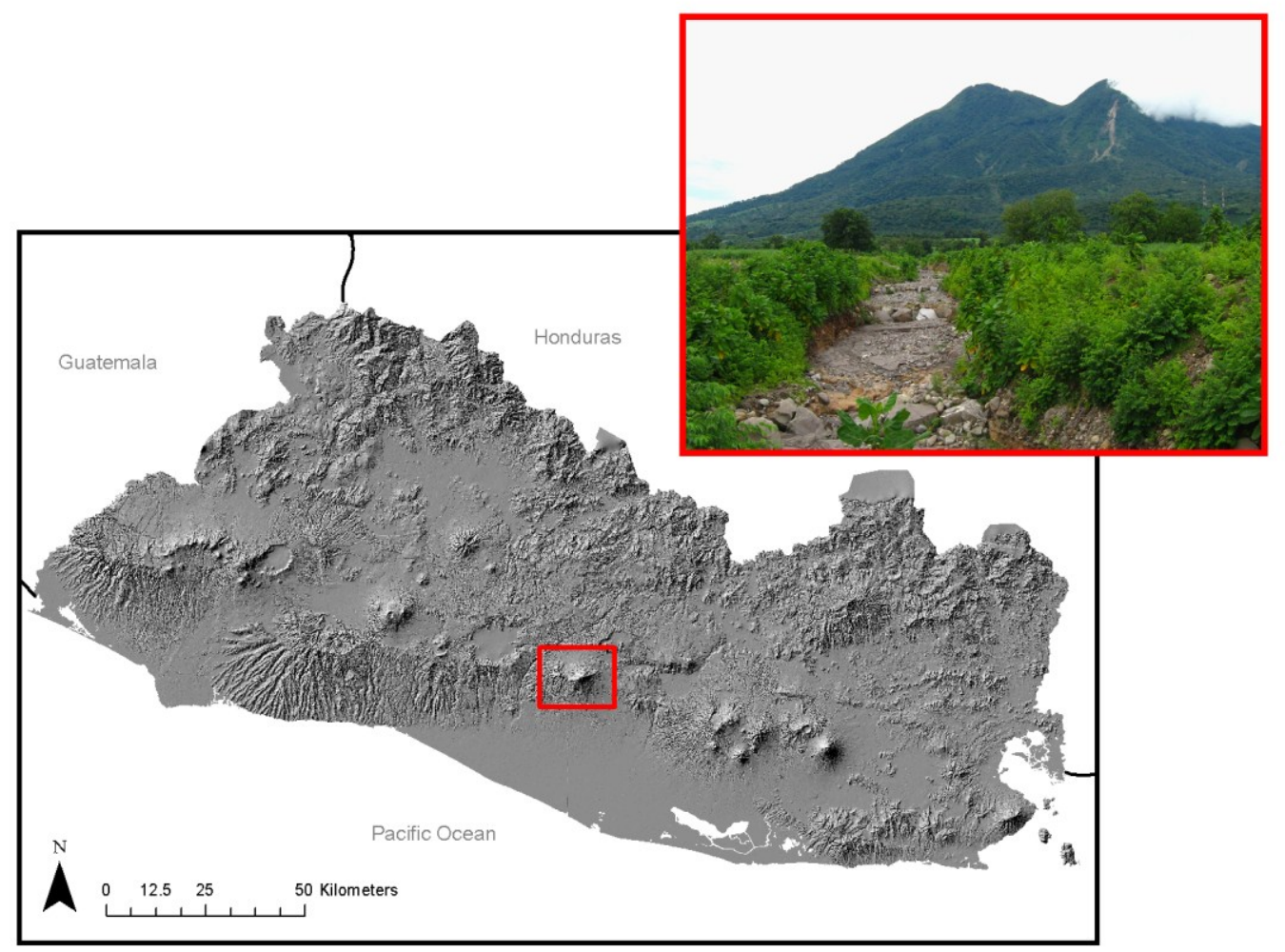

Figure 2.1: Study location in central El Salvador. Inset photo shows San Vicente volcano with landslide scar visible on right cone of the volcano and debris flow channel in the lower left. Photo by $D$. Smith 
As noted, the problems of rainfall-induced shallow landslides and debris flows in volcanic terrains are of significant concern in El Salvador, particularly near the major volcanoes. Major et al. (2004) reports at least 20 rainfall-initiated debris flows in recent recorded history: 2 on San Salvador Volcano, 11 on San Miguel Volcano and 7 on San Vicente. Two notable historic events on the San Vicente volcano accounted for in this total are the 1934 debris flows in the community of Tepetitán and the 2001 flows in the town of Guadalupe.

The Tepetitán flows from 1934 are believed to be rainfall-induced, and they destroyed much of the village, necessitating reconstruction in a new location which is still on the same alluvial fan (Jibson et al. 2004). The 2001 events in Guadalupe were a rainfallinduced mobilization of material deposited by the large January and February earthquakes of that same year. These debris flows were responsible for killing at least two people, and destroyed temporary shelters and other buildings on the northeast part of town (Crone et al. 2001). The largest and most destructive debris flows that have occurred in recent history on the San Vicente volcano are those associated with Hurricane Ida in 2009.

\subsubsection{Background and Motivation}

In November 2009 Hurricane Ida passed through the region of San Vicente volcano, dumping more than $480 \mathrm{~mm}$ of rain on the upper slopes of the volcano in less than two days, with a peak rainfall intensity of over $80 \mathrm{~mm} / \mathrm{hr}$ (Schweig et al. 2010). During the peak intensity of this storm, shallow landslides high on the western cone (see Figure 2.2 for location) of the volcano initiated a series of destructive debris flows during the early morning hours of November 8 . These debris flows tore through several of the communities on the northern flanks of the volcano, causing much destruction in the communities of Verapaz and Guadalupe, and were responsible for over 200 deaths.

The debris flows associated with Ida triggered an outpouring of support and resources to better prepare and educate the local population for possible future events. In the time since, numerous Non-Governmental Organizations (NGOs) as well as the newly formed Salvadoran Civil Protection agency have been holding trainings and workshops with the communities most affected in the past and at risk in the future. In addition to these trainings and support, it is necessary for organizations and individuals making decisions during times of elevated risk to have the best information available to make an informed decision. This work fills in some of the gaps and will provide a tool that these individuals and organizations can use as part of the decision making process. 


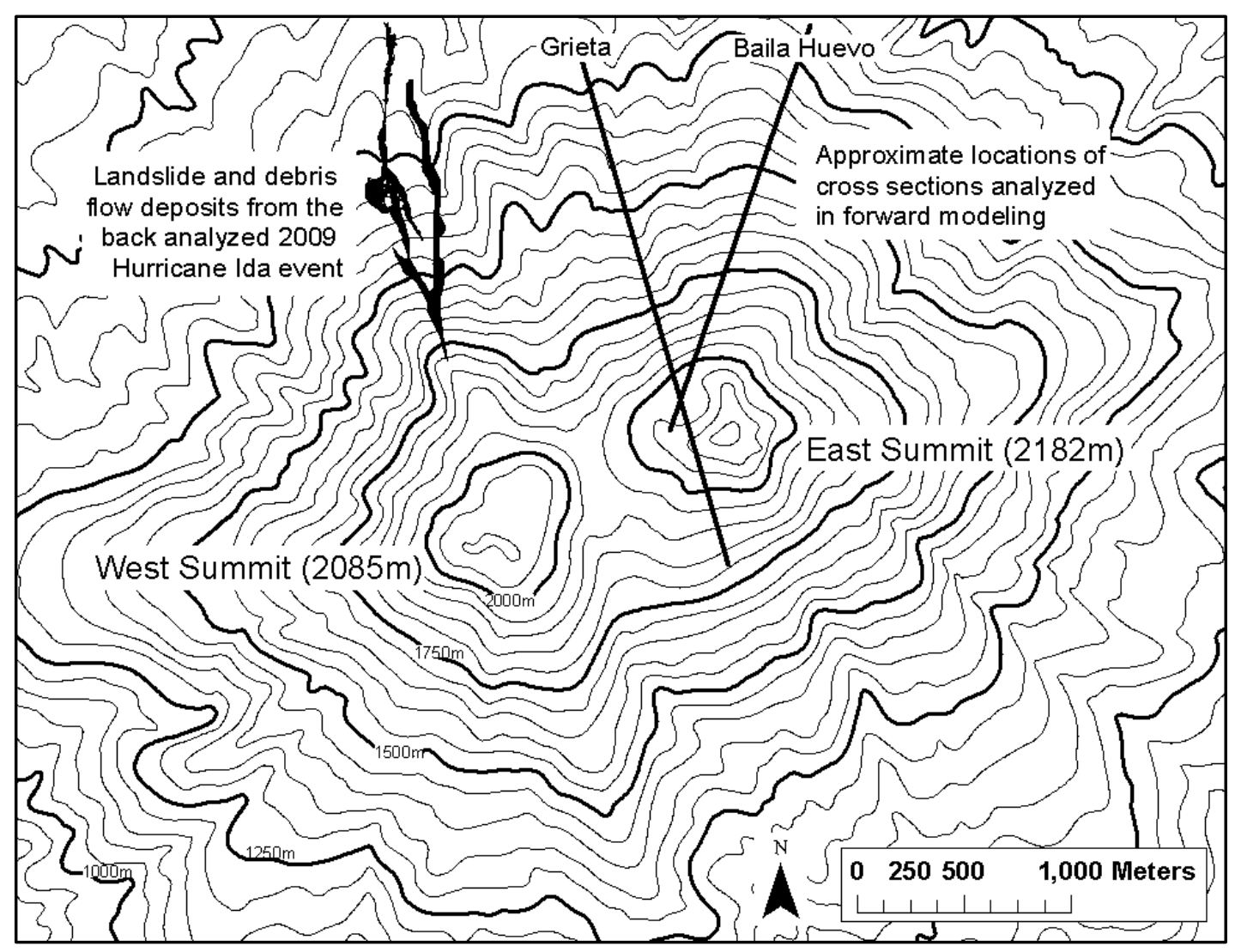

Figure 2.2: Contour map of the upper slopes of the San Vicente volcano. The distinct double cone shape of the volcano is apparent along with the very steep slopes on all sides. 2009 Hurricane Ida landslide shown, along with approximate locations of forward modeling sites

The objectives of this research were threefold:

1) Back analyze the shallow landslides that occurred during Hurricane Ida to determine the critical thresholds of the various destabilizing factors (rainfall, groundwater location, etc.) that trigger slope instability at San Vicente Volcano.

2) Evaluate the rainfall-induced landslide hazard on the northwest flank of the San Vicente Volcano

3) Develop a useful tool for the Salvadoran stakeholders to determine the hazard from rainfall-induced slope instability on the northwest flank of San Vicente Volcano which in turn would help to determine the communities at risk in an emergency event.

Geographic Information System (GIS) based spatial analysis methods are commonly used for evaluating slope instability and debris flow potential. This method typically uses past records of slope instability and geomorphological criteria, such as slope angle, soil type, 
maximum rainfall, etc. (Gabet and Mudd 2006; Godt et al. 2008; Larsen and Simon 1993; Montgomery et al. 1998). The output of these GIS analyses is empirical and reported as a likelihood of occurrence based on the given situation. These models predict that there either will or will not be slope instability based on the input parameters, and are a simple and effective way to know when a few key criteria that commonly cause slope instability are met. This approach has been widely used by the United States Geological Survey (USGS) on the Cascade volcanoes in the Pacific Northwest as well as in other debris flow prone areas of the United States, and has been applied in developing countries like Honduras and Micronesia (Harp et al. 2009). GIS based spatial analysis is effective when there is sufficient inventory of past events and detailed data on geomorphological criteria. However, in places like El Salvador, where there is limited data availability outside of the capital city region and not enough of an inventory of past events, it can be difficult to create an effective GIS based model.

Another major limitation of a GIS based approach is the fact that typically it does not consider the strength properties of the various soils in the region. Godt et al. (2008) has demonstrated that when site-specific information can be obtained, a model that takes into account more of the strength properties of the soil would prove beneficial (Godt et al. 2008). Additionally, being empirical in nature, the GIS-based models typically are not governed by the physics of transient groundwater and geotechnical slope stability analysis. This project approaches the issue of rainfall-induced shallow landslides and the potential resulting debris flows from a different angle than is typically pursued. Because of the remote nature of the study area, much of the information that would be required to create an effective model using these methods is lacking. A slope stability analysis was performed on the areas that experienced landslides in 2009. Using this analysis, the variables involved in the initial slope failure were isolated. These conditions were then applied with forward modeling to evaluate the potential hazard.

The current hazard assessment for debris flows on the San Vicente volcano was provided by the USGS in the form of a general map showing potential inundation areas for debris flows of three given volumes initiating from any of the major valleys and drainages coming from the volcano (Major et al. 2004). The volumes used in this assessment are based on estimates from past events and no particular attention is given to specific areas of failure initiation or communities that would be impacted the most. As provided and utilized concurrently with established rainfall thresholds, this is a very useful tool for planning purposes and community awareness if it is known where the failure is going to initiate. However, with the current tools, there is critical gap for decision makers to decide where the next failure would initiate during a storm event. This information is important to develop timely evacuation plans and to communicate the risk of slope instability to communities. This research seeks to answer that critical need.

This study focuses on the development of a tool that decision makers in Civil Protection or even community leaders who were a part of monitoring and reporting could use during an event to evaluate the current hazard presented by a storm. This tool is based on Limit Equilibrium-based slope stability analysis that accounts for the transient groundwater conditions during rainfall. This tool allows using the initial water table location and the 
cumulative rainfall totals to determine the likelihood of a possible slope failure and factor that into evacuation plans. The sensitivity of the base model to various factors is analyzed, and an example final tool is given, along with suggestions for improving the framework for future application elsewhere.

\subsection{Study Area}

The San Vicente volcano is a paired stratovolcano covered by coffee plantations and dense cloud forest continuing to the 2182 meter summit. The last known activity of the volcano is approximately 1,700 years ago (Major et al. 2001). See Figure 2.1 for approximate location of the volcano and the study area within El Salvador. In this study, the northern flank of the volcano is focused on as the subject of research. On the northern flanks, at multiple locations high on the eastern cone, local workers in the coffee plantations have noticed large cracks forming near the tops of several drainages. These cracks are believed to be surface tension cracks. The cracks have been steadily growing, up to several centimeters in width and unknown in depth, monthly in the rainy season, and are of great concern. Their location above drainages that could devastate the communities of Verapaz, Tepetitán and parts of the city of San Vicente makes understanding the potential for slope instability and debris flows critical.

\subsubsection{Geologic Characteristics and Volcanic Structure}

The central volcanic chain is one of the major geologic and geographic regions of El Salvador. This chain of volcanoes is situated in a line paralleling the coast about $170 \mathrm{~km}$ from the Middle America Trench (Figure 2.3), where the Cocos Plate is subducting beneath the Caribbean Plate and includes the Santa Ana, San Salvador, San Vicente and San Miguel volcanoes as well as several other areas of past volcanism. The volcanic arc dominates the geology and soil structure of the region, creating steep slopes that are susceptible to landslides and debris flow events.

Because it is inactive and is not believed to pose an imminent eruptive threat, the San Vicente volcano is notably less studied. The internal structure of the volcano is not well documented, but the core of the volcano is believed to consist mainly of andesitic lava flows and pyroclastic deposits associated with past eruptive activity of San Vicente (Rotolo et al. 1998). This core is overlaid with a relatively thick $(\sim 25 \mathrm{~m})$ layer of more recent pyroclastic and ash deposits from past eruptions of San Vicente interbedded with deposits from the nearby Ilopango caldera. These deposits, known collectively as the Tierra Blanca (TB) series are very common in the central part of El Salvador and are widespread to the west of the Ilopango caldera in the capital city San Salvador, as well as 
in the entire Jiboa Valley region east of the caldera on the north slopes of San Vicente (Rolo et al. 2004).

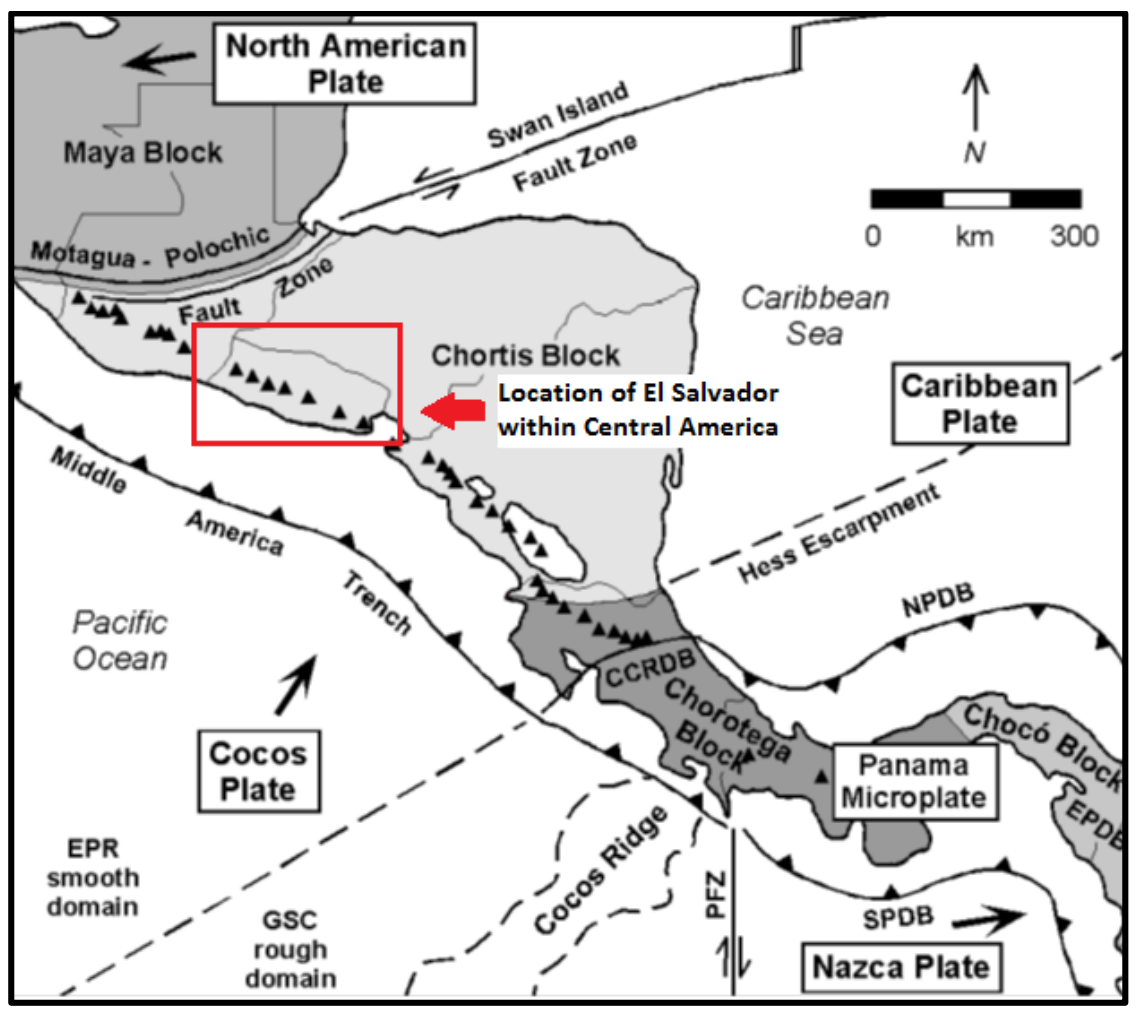

Figure 2.3: Regional geology and tectonic setting of EI Salvador. The central volcanic chain is represented as triangles. Modified with permission from (Marshall 2007)

As mentioned previously, the volcano has a recurring and destructive pattern of landslides and debris flows occurring on the northern slopes of the volcano (Crone et al. 2001; Jibson et al. 2004; Major et al. 2004; Scott et al. 2005). Smaller debris flows that remobilize from past deposits are relatively common higher on the volcano and there have been at least 10 major events recorded in the last 250 years (Bommer and Rodriguez 2002; Major et al. 2004). As Figure 2.2 indicates, this pattern is not surprising given the very steep slopes of each cone, up to $60^{\circ}$ or more in places, with $40^{\circ}$ slopes very common. Combined with El Salvador's location in the tropics and regular seasonal exposure to the intense rains of tropical storm events, this creates a recipe for disaster. 


\subsubsection{Climatic Conditions}

El Salvador experiences a tropical climate as is found at similar latitudes worldwide. This climate is characterized by a distinct wet and dry season. The majority of annual precipitation occurs during the wet season, which typically lasts from May until November each year. Coincident with the rainy season is the hurricane and tropical storm season for the northern Atlantic and Pacific Oceans. Every few years a major hurricane or tropical storm affects El Salvador with intense rainfall, flooding and potentially landslides. Events of the last 15 years include Hurricanes Mitch (1998), Stan (2005), Adrian (2005) and Ida (2009) as well as Tropical Depression 12E (2011). As described above, Hurricane Ida produced the highest measured intensities of rainfall in central El Salvador in recent history, a major factor in the destructive landslides that occurred during the storm.

\subsection{Data and Method}

In this study, the evaluation of the past and the potential for future landslides on the north slopes of San Vicente were analyzed using 2D limit equilibrium based slope stability coupled with Finite Element Method (FEM) based transient groundwater modeling. The inputs for this analysis including material properties, slope geometry etc., were obtained from a combination of field data collection and literature evaluation. The focus of the field data collection was to understand the internal structure of the volcano and the geotechnical properties of the various soil layers overlaid on the volcano. In this field campaign, efforts were also made to identify the past failure and its dimensions. Further, back-analysis was performed using the information on the past failure together with the estimated geotechnical properties to estimate the unknown parameters. Additionally, these parameters were used for a systematic analysis of the slope stability of north slopes of San Vicente and to establish the relation between the stability of the slopes, groundwater level, cumulative rainfall, and rainfall intensity.

\subsubsection{Field and Laboratory Work}

In May 2012, a collaborative field campaign was organized to visit the San Vicente volcano and the areas specifically affected by the 2009 debris flows. The participants in the field campaign included: representatives from the local civil protection, the University of El Salvador, national police and the stakeholder communities. Work performed during this field campaign included field permeameter tests for hydraulic conductivity, vane shear tests for undrained shear strength and collection of soil samples for laboratory testing. These tests were chosen to provide a reasonable estimate of the material properties, considering the remote and often nearly inaccessible situations at site. 
The sites visited included the initiation zone of the 2009 debris flows, as well as several locations around the volcano where suspected tension cracks were forming but no large failures have yet occurred. See Appendix A for a detailed report of the field work completed.

Samples of the different encountered materials at each field site were brought back for laboratory testing. The samples were small and were not intact, restricting some of the available testing methods. A grain size analysis was performed on the available samples materials. Occasionally more information was necessary than was available from the field work completed. This information was obtained from a comprehensive previous study of engineering characteristics of the Tierra Blanca deposits (Rolo et al. 2004). The material properties borrowed were based on grain size distributions and material descriptions in this resource. The grain size distributions for the various samples collected from San Vicente can be found in Appendix B.

\subsubsection{Rocscience Slide Modeling}

The field campaign and laboratory testing provided a better understanding of the physical layout of landslide-prone areas, the material properties and their distribution. Using this information a 2-D slope stability model of the volcano was created using Slide v6.011 (Rocscience 2011). This model was used to constrain and quantify as best as possible the failure mechanisms for the slopes.

The structure of the volcano is not well documented, especially higher up where shallow slope failures occur. The model was constructed using a simple approach that minimized assumptions and took all known characteristics into account, representing the materials of the slopes. Based on observation of small outcrops in multiple locations and conversation with locals who were familiar with the terrain, it can be assumed the soil profiles are very similar in most areas.

The typical cross section used consists of three main layers as illustrated in Figure 2.4:

1) Tierra Blanca Joven (TBJ): The youngest Tierra Blanca deposits can be found to a depth of several meters everywhere on the northern slopes of the volcano

2) Weathered volcanic soils: Below the TBJ, other older Tierra Blanca deposits as well as deposits from past activity on San Vicente volcano can consistently be found up to a depth of $\sim 25 \mathrm{~m}$

3) Lavas and pyroclastic rock: Beneath the two volcanic soil layers is a more or less solid core of lavas and older, denser volcanic rock. 


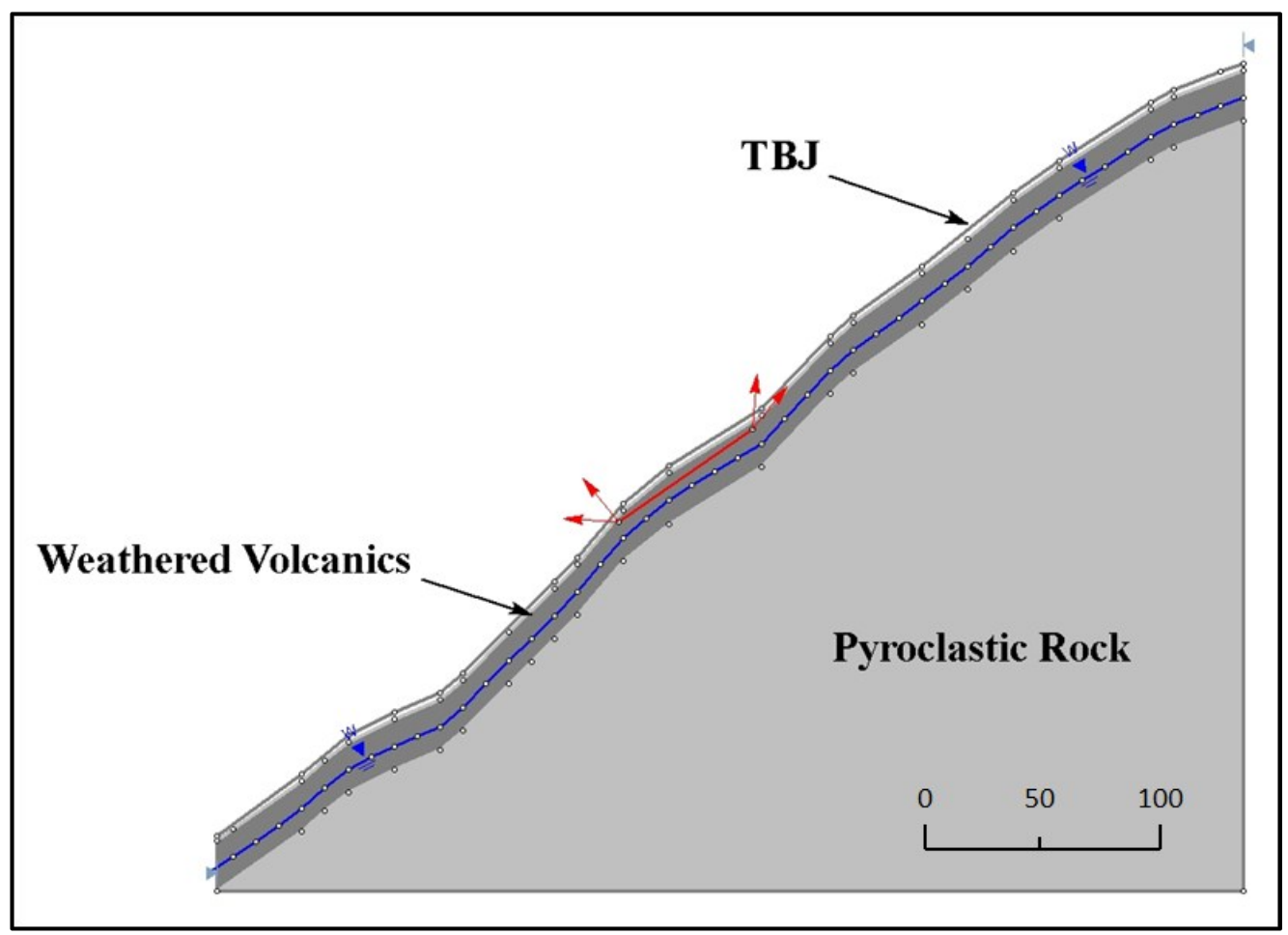

Figure 2.4: Typical cross section used for slope stability analysis. The red arrows indicate the boundaries of the back analysis. TBJ stands for Tierra Blanca Joven. Scale is in meters.

Each material type used in the model was defined using a classification method for slope stability of volcanic material proposed by Del Potro and Hürlimann (2008). This approach outlines four basic material types: lava, autoclastic breccia, pyroclastic rock and volcanic soil. These material categories are based on the geotechnical behavior of each material. The categories allow for variance to match specific conditions. In this study, the suggested categories were consulted when classifying the slope model of San Vicente. Using these categories the upper two layers of this model, TBJ and weathered volcanic soils, were classified as volcanic soils while the inner part of the volcano was classified as a dense pyroclastic rock or lava.

The volcanic soil layers were assigned similar properties based on grain size analysis and literature values, outlined in Table 2.1. Due to the additional weathering found in the weathered volcanic soils, a higher friction angle was used, representing the higher degree of cementation witnessed in this material. Both materials are assumed to be non-cohesive based on observation, vane shear test and literature review (Rolo et al. 2004). The field permeameter tests verified that both the materials have similar hydraulic conductivity. The thickness of TBJ was based on field observation, and the $25 \mathrm{~m}$ overall depth of volcanic soils was based on geophysical data (resistivity and seismic reflection) collected in November 2011 near the observed tension cracks on the eastern cone of San Vicente. This geophysical data suggests that the unconsolidated soil exists to a depth of about $25 \mathrm{~m}$ and denser material is present beneath it (Kruse 2011). By using the suggested 
classifications mentioned above, any unknown material properties in the model that were not borrowed from Rolo et al. (2004) were assumed from the typical values reported from del Potro and Hürlimann (2008). In keeping with the simplicity of the model and lacking any information suggesting otherwise, the layer thicknesses were kept constant throughout each profile. The material properties are summarized in Table 2.1

Table 2.1: Summary of material properties for volcanic soils used in model. An asterisk (*) before property indicates property derived from literature values

\begin{tabular}{lccccc}
\hline Material & $\begin{array}{c}\text { Thickness } \\
(\mathrm{m})\end{array}$ & $\begin{array}{c}\text { Cohesion } \\
(\mathrm{kPa})\end{array}$ & $\begin{array}{c}* \text { Friction } \\
\text { Angle } \boldsymbol{\varphi} \\
(\text { degrees })\end{array}$ & $\begin{array}{c}* \text { Unit Weight } \\
\left(\mathrm{kN} / \mathrm{m}^{3}\right)\end{array}$ & $\begin{array}{c}\mathbf{K}_{\text {sat }} \\
(\mathrm{m} / \mathrm{s})\end{array}$ \\
\hline TBJ & 3 & 0 & 35 & 13 & $4.6 \times 10^{-5}$ \\
$\begin{array}{l}\text { Weathered } \\
\text { Volcanics }\end{array}$ & 22 & 0 & 38 & 13 & $4.6 \times 10^{-5}$ \\
\hline
\end{tabular}

To evaluate the unsaturated behavior of the soils during the transient analysis it was necessary to create a soil water characteristic curve (SWCC) for each material. Using a method outlined in Chin et al. (2010) for non-plastic soils, the Fredlund \& Xing SWCC parameters $a, m$ and $n$ were calculated using the grain size distribution (Chin et al. 2010; Fredlund and Xing 1994). The grain size distributions were obtained from laboratory analyses and Rolo et al. (2004). The calculation of Fredlund \& Xing parameters was done using equations $5 a-5 h$ from Chin et al. (2010) and compared to typical reported values in literature for similar soil types. These parameters were calculated for both soils modeled, TBJ and weathered volcanics. This method provided an approximation of the Fredlund \& Xing parameters, which was used to develop the SWCC for each material in the analysis. The SWCC were created by Rocscience Slide using the Fredlund \& Xing parameters. The program uses the Fredlund \& Xing equations to create the curves, and the user only need obtain the $a, m$ and $n$ for each material. This SWCC is then applied during the different stages of the stability analyses, to compute the unsaturated shear strength dependent on the estimated moisture content at each stage in the transient groundwater analysis. Table 2.2 contains the Fredlund \& Xing parameters used for this study. 
Table 2.2: Fredlund \& Xing parameters used to create SWCC

\begin{tabular}{rccc} 
& $\boldsymbol{a}$ & $\boldsymbol{m}$ & $\boldsymbol{n}$ \\
\hline TBJ & 7.93 & 0.81 & 1.36 \\
$\begin{array}{r}\text { Weathered } \\
\text { Volcanics }\end{array}$ & 7.06 & 0.82 & 1.52 \\
\hline
\end{tabular}

Appendix $\mathrm{C}$ contains supporting calculations outlining the methods used to find hydraulic conductivity of the materials as well as the development of the SWCC parameters.

\subsubsection{Back-Analysis}

With material properties established, it was possible to back analyze the shallow landslide that occurred during Hurricane Ida. This analysis was performed using the Limit Equilibrium Method (LEM) and took into account actual rainfall data from Hurricane Ida and the failure surface estimated from the field visit. The location of the 2009 landslide can be found on Figure 2.2. The profile analyzed is seen in Figure 2.4, with the failure surface bounded by the paired arrows shown in the middle of the section. The arrows represent the failure area used in the back analysis, which was based on field observations. This analysis provided insight into two major unknowns: depth to water table and appropriateness of assumed material properties, specifically sensitivity to changes in friction angle, $\varphi$. Because of the lack of groundwater monitoring well data it was critical to determine depth to water table.

The back analysis was performed using a block search method with a non-circular failure surface. This failure method mimics the translational failures seen commonly in shallow landslides. This method also allowed for analysis of uncertainty in exact failure surface. A failure line at a depth of about 5 meters was used, and the upslope and downslope angles of potential failure surfaces were varied to account for numerous failure scenarios. The method utilized for the LEM analysis was the Bishop Simplified method. This method is commonly used in 2-D slope stability analyses and is typically found to be conservative for non-circular and irregular slip surfaces, making it a good choice for this application (Hungr et al. 1989). The program chooses the failure surface that has the lowest Factor of Safety (FOS) of all possible surfaces. The Factor of Safety is a ratio of available shear strength of a material to the shear strength required for equilibrium in a given scenario. Because of inconsistencies in geologic materials, a FOS of 1.0 or higher cannot necessarily be assumed stable. Recommendations for relative stabilities in slope analysis have been given to evaluate slopes: Typically slopes with a FOS $>1.5$ are said to be stable. Slopes with $1.3<$ FOS $<1.5$ are said to be moderately unstable, and $1.0<$ FOS $<1.3$ are said to be inherently unstable. A FOS $<1.0$ means that the slope is at failure (Hoek 2007). 
The back analysis showed that, as expected, the stability of the slopes has a drastic response to intense rainfall events. Because hourly data was available for the transient groundwater analysis and the approximate time window of the slope failure was known, it was possible to vary the water table in the analyses to find a reasonable initial water table elevation that calibrated the model to actual events. The time of slope failure corresponded to the highest rainfall intensities, around 35 hours into the rainfall event, and the model finds that an initial water table elevation approximately $15 \mathrm{~m}$ below the surface provided a simulation that followed this pattern. This value matches estimates made by locals familiar with regional hydrology and falls in with the observance that steep residual soil slopes typically have a deep groundwater table and large unsaturated zone (Rahardjo et al. 2010). The estimated depth to water table at time of failure ranges from $2-4 \mathrm{~m}$. It is important to note that this depth is based only on the assumptions that have been listed above that were factored into the model, and do not account for antecedent moisture conditions, which considerably affects slope stability (Collins and Znidarcic 2004; Rahardjo et al. 2007; Rahimi et al. 2011). Figure 2.5 provides insight into the changes in the Factor of Safety (FOS) with cumulative rainfall from Hurricane Ida and Figure 2.6 details the failure surface associated with initial water table at $15 \mathrm{~m}$.

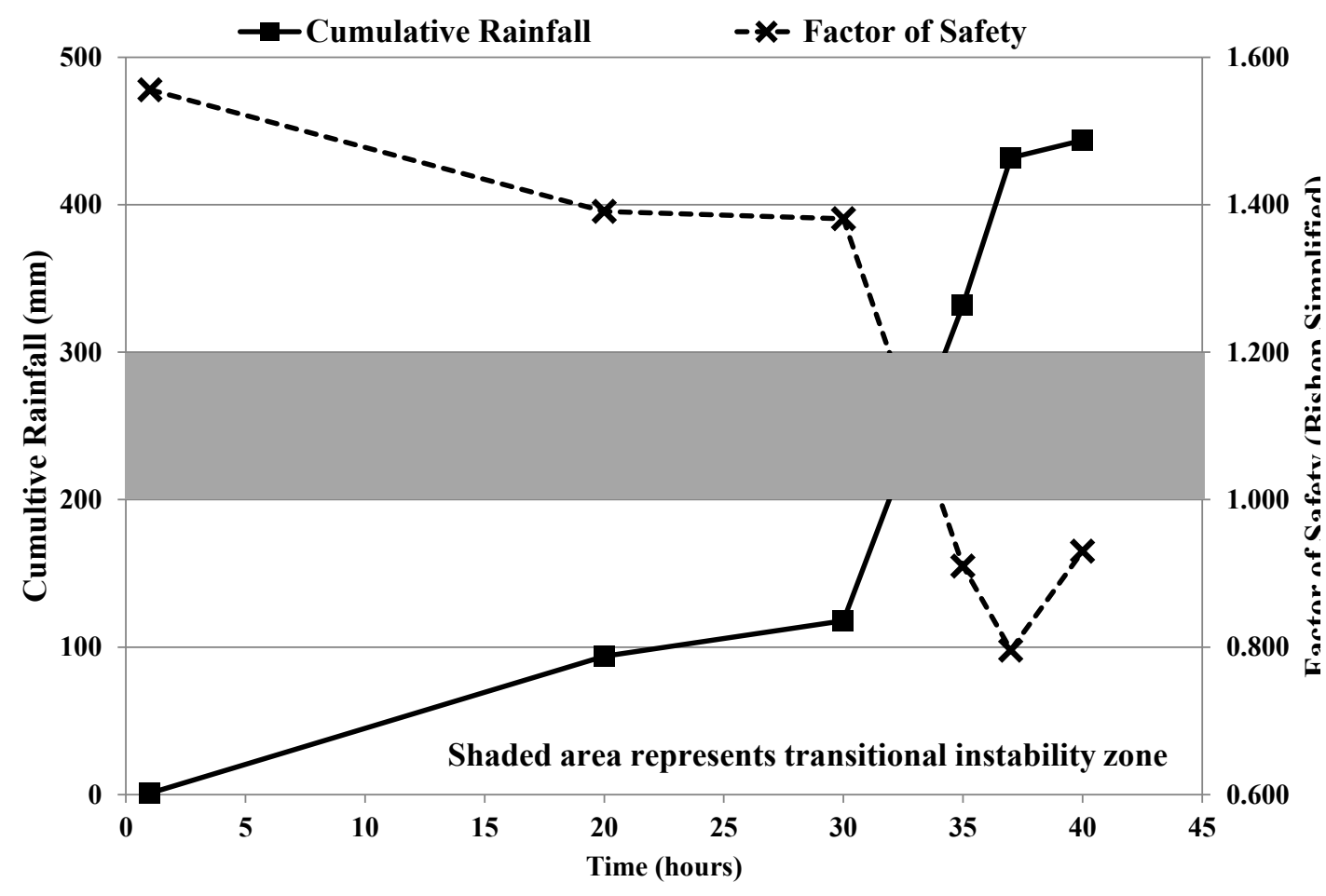

Figure 2.5: Cumulative rainfall from Hurricane Ida and FOS for back analysis with water table at a depth of $15 \mathrm{~m}$ 


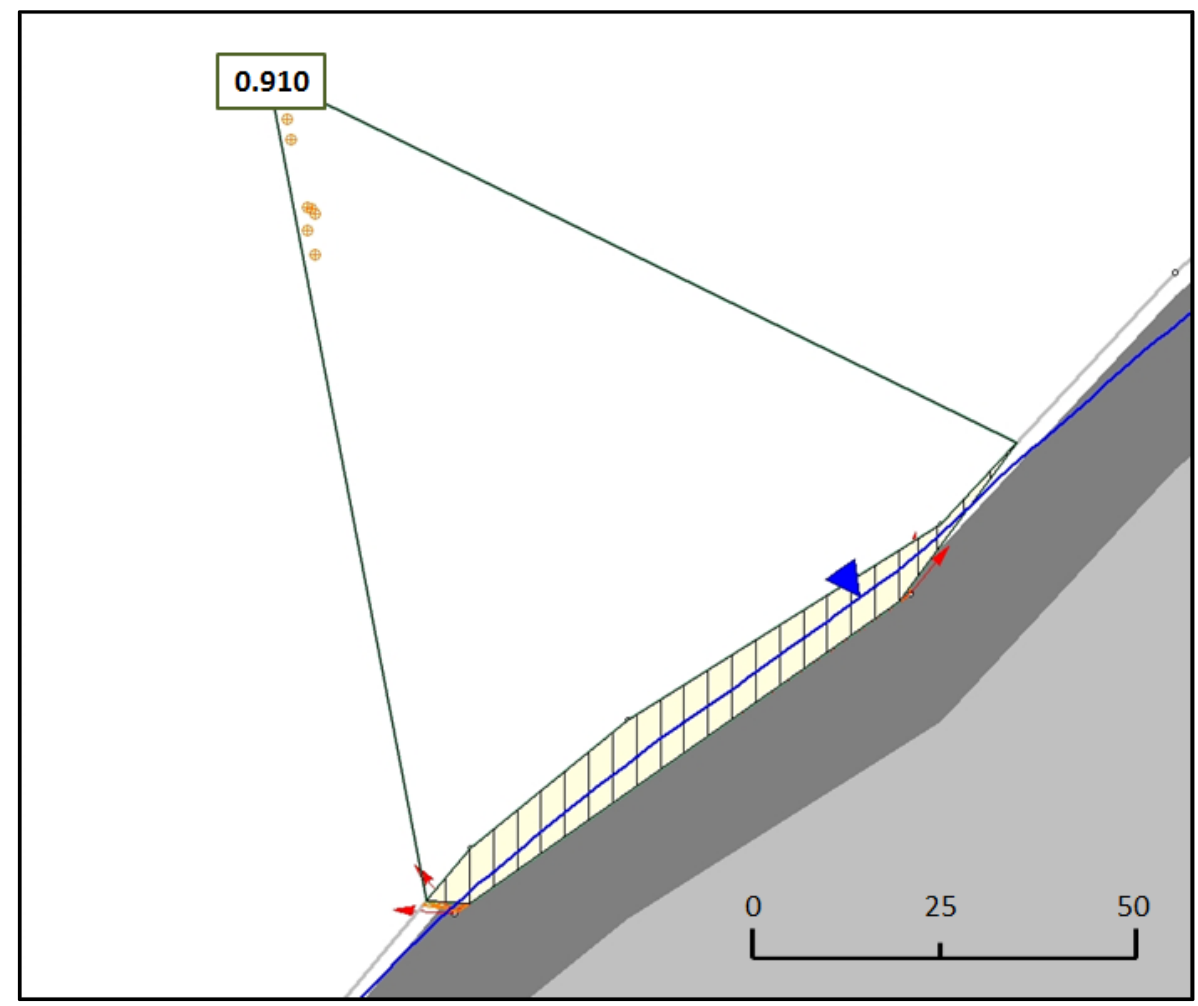

Figure 2.6: Back analysis cross section showing failure surface at time 35 hours. The resultant FOS is 0.910 and the water table is at a depth of $5 \mathrm{~m}$. Scale is in meters.

The assumptions that were used in the model were simplifying in nature and were always based on the best available information. This was done in order to keep modeling results conservative in the face of uncertainty. The simplifying assumptions that were believed to have the biggest potential impact on minimum FOS included constant soil thickness and constant initial depth to water table throughout the profile, as well as an assumed constant precipitation rate along the entire surface of the profile. These conditions were used to provide redundancy in the model and give conservative results for estimating the stability of the slopes. Variations of each of these parameters were modeled in order to assess the possible effects of simplification. The profile was modeled with varying soil depths and varying water table. These variations were tested at up to $+/-10 \mathrm{~m}$ from the original. The effects of varying precipitation along the profile were also tested. Example cross sections of these scenarios can be seen in Figure 2.7. 
a)
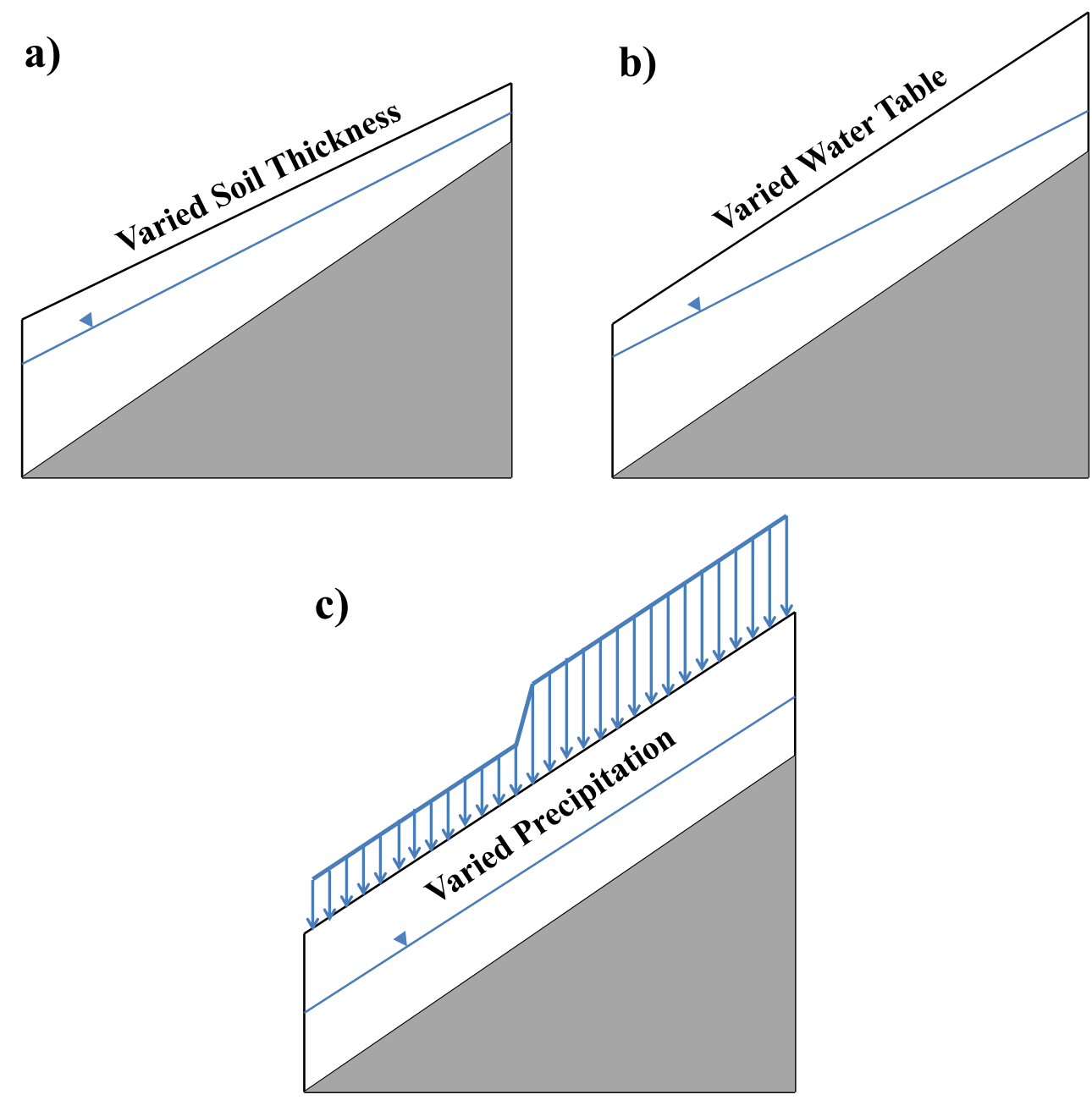

\section{Figure 2.7: Variations of back analysis cross section modeled. Results for each are shown in Table 2.3}

As seen in Table 2.3 the results, several of the potential variations had marked effects on the model outcome. Varying the soil depth (simulating thicker soil deposits lower on the slopes and thinner higher up, while keeping the average at $25 \mathrm{~m}$ ) resulted in a FOS $18 \%$ higher. Varying the water table depth (simulating a deeper water table higher on the slopes and shallower water table lower) resulted in a FOS $28 \%$ higher for average $15 \mathrm{~m}$ depth, and a FOS $9 \%$ lower for average $12.5 \mathrm{~m}$ depth. These results for an average depth of $15 \mathrm{~m}$ were significantly higher than a constant water table depth of $15 \mathrm{~m}$, but raising the water table 2.5 meters produced a drastic drop in FOS. Notably, the effects of varying precipitation with altitude were significant. To simulate possible orographic effects on rainfall, the precipitation on the lower half of the cross section was reduced to $50 \%$ of what was occurring on the upper slopes. This variation resulted in a $32 \%$ higher FOS. Also notable was the large difference in model results when using a varying water table. With the exception of using a $12.5 \mathrm{~m}$ deep water table, these variations all resulted in 
higher FOS values, meaning that the model was conservative in all cases. The possible impacts of these variances are further discussed later in this paper.

Table 2.3: Select FOS results at time of failure using varied model construction

$\begin{array}{cc}\text { Factor of Safety } & \text { Difference from } \\ \text { (Bishop Simplified) } & \text { initial model }\end{array}$

\begin{tabular}{rcc}
\hline $\begin{array}{l}\text { No variations } \\
\text { Varied water table } \\
\quad \text { average } 15 \mathrm{~m})\end{array}$ & 0.910 & $\mathrm{n} / \mathrm{a}$ \\
$\begin{array}{r}\text { Varied water table } \\
\text { (average 12.5m) }\end{array}$ & 0.854 & $28 \%$ \\
$\begin{array}{r}\text { Varied precipitation } \\
\text { Varied soil thickness }\end{array}$ & 1.370 & $-9 \%$ \\
\hline
\end{tabular}

The sensitivity of the back analysis model to the input material properties were analyzed by varying the friction angle and cohesion. These analyses showed little sensitivity of the slope's stability to variance of the friction angle or cohesion within typical values reported by Rolo et al. (2004). Typical values reported for similar soils to those modeled in this study were found to have friction angles of 35 or 36 degrees and cohesion of 10 $\mathrm{kPa}$ or less (Rolo et al. 2004). Varying the friction angle between 35 and 40 degrees did not produce any changes in FOS of more than $11 \%$. Using a value of $10 \mathrm{kPa}$ for cohesion, the maximum expected value based on similar soils, the FOS varied only $12 \%$. Based on these effects, neither of these material properties was considered as a significant factor in the analysis. These results are shown in Figure 2.8. When the effects of all the various parameters and model constructions on model output were compared to the effects of simply varying the initial water table depth, it became clear that the elevation of the water table was the dominant unknown factor in this analysis.

The results seen in Table 2.3 and Figure 2.8 both show that the model, as used, returns results that are conservative. In other words, the calculated FOS from using the model as constructed from back-analysis is generally lower than the variations that could be used. In disaster preparation, it is important to adopt conservative estimates in order to avoid a situation where something occurs that was not expected based on available information. Basing decisions off of conservative estimates minimizes the risk from a potential disaster. 

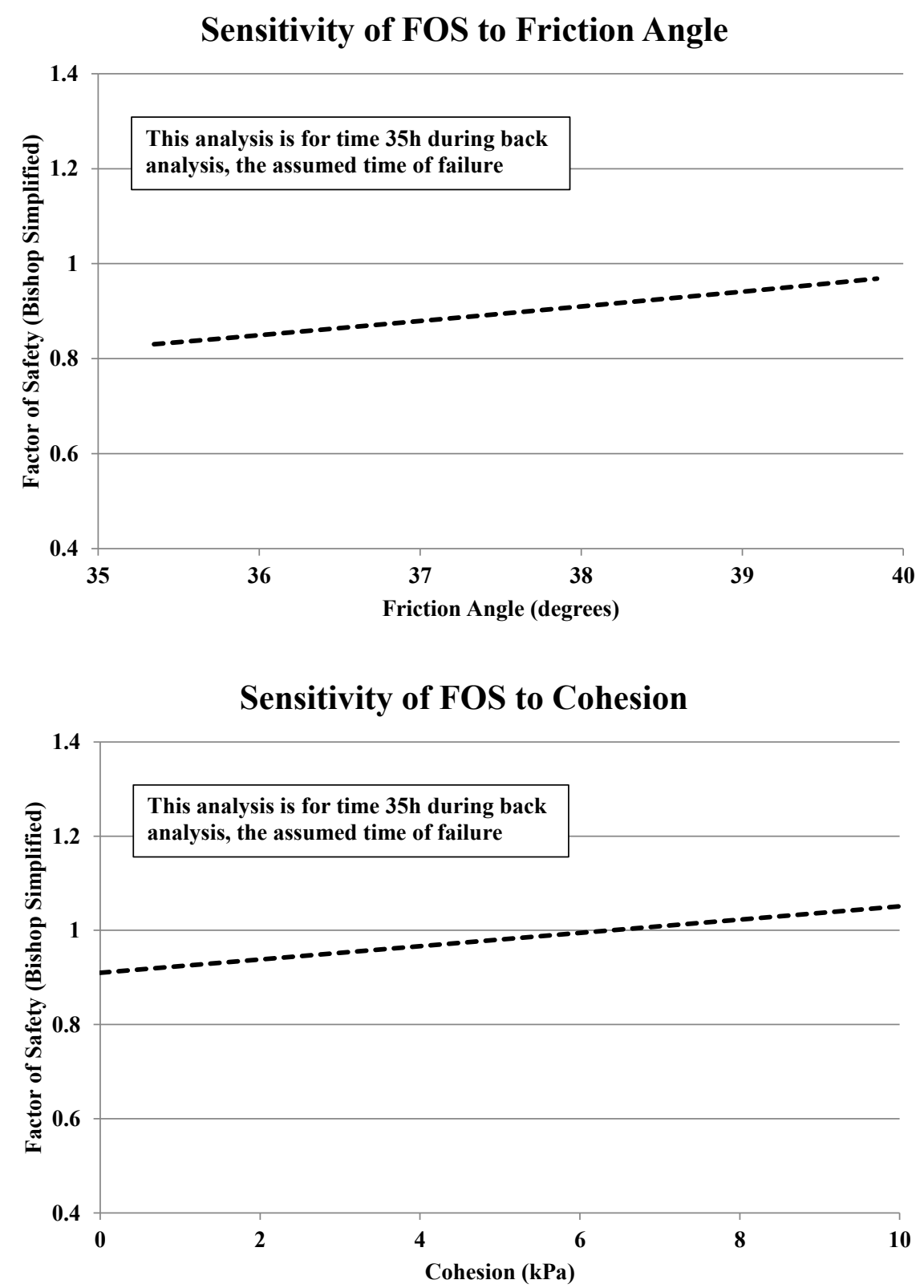

Figure 2.8: Sensitivity Analysis of FOS to friction angle and cohesion at time of failure during back analvsis of existing landslide from Hurricane Ida

\subsubsection{Forward Modeling}

The back analysis of a shallow landslide caused by Hurricane Ida in 2009 enabled estimation of the depth to ground water table and evaluation of the geotechnical properties of the various soil layers. Further, this data was used for analyzing potential 
landslides on the northeast flank of the volcano in several locations where there are concerns for future landslides and debris flows. Given the limitations of the model, available stratigraphic and geotechnical information, and the real-time groundwater and rainfall monitoring capabilities of the Salvadoran agencies and stakeholders, a form of stability chart was determined to be the most potentially useful tool in the event of extreme rainfall. This chart would outline the conditions that could potentially produce shallow slope failures leading to debris flows on the volcano, and could be used in realtime as agencies monitor a storm. From the back analysis it was apparent that cumulative rainfall, rainfall rate and initial groundwater table were the important variables to include in the stability chart.

Hourly rainfall data from the volcano were available for the years 2005-2010 (SNET 2011). A detailed review was carried out of the tropical storms and hurricanes that affected central El Salvador during this time. Several periods within those six years were missing, but included within available data were two major storms that dumped more than 400mm of rainfall each: Hurricane Ida in 2009 and Hurricane Adrian in 2005. As has been discussed earlier, Hurricane Ida caused several large and destructive debris flows while there is no record of any destructive events associated with Adrian.

Both of these hurricanes had single continuous rainfall events that produced approximately $350 \mathrm{~mm}$ of precipitation in less than a day, but there is a marked difference in the distribution of that rainfall. The intense event associated with Ida was only about 12 hours long, and had a one hour peak intensity of $81 \mathrm{~mm} / \mathrm{hr}$, while the peak rainfall event in Adrian was 18 hours long and contained a prolonged period of 8 hours with rainfall intensities of $30 \mathrm{~mm} /$ hour. These two storms were used as the models for extreme cases of two basic storm types: a shorter storm that has a burst of very intense rainfall, and a more drawn out event that has a period of prolonged medium intensity precipitation. Figure 2.9 shows the base designed storm used during modeling for each case. 


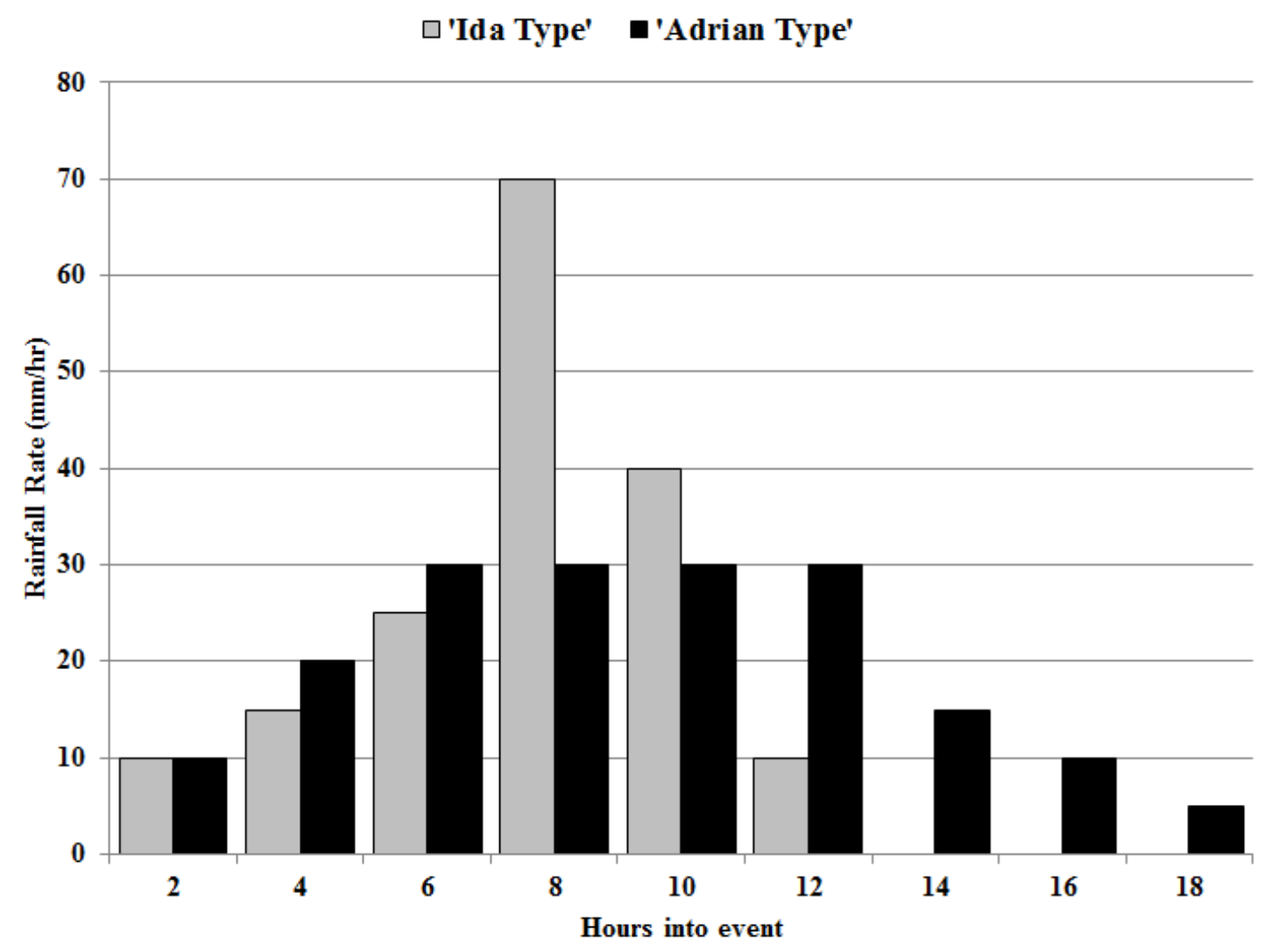

Figure 2.9: Base designed storms used to mimic the distinct rainfall distributions of Hurricane Ida (distinct peak of high intensity) and Hurricane Adrian (no distinct peak, but prolonged mid-intensity)

Utilizing the designed rainfall events described above, an iterative transient slope stability analysis was performed to develop the stability chart. The Slide program is capable of using a finite element transient groundwater analysis. A mesh was created using the cross section and boundary conditions were assigned. The program then used these conditions and calculated pore pressures and water table locations at predetermined intervals. For this analysis a time step of 2 hours was used. At each time step, the water balance was calculated for the mesh, and using this information a slope stability analysis was performed (Rocscience 2011).

This analysis was performed to present an example of a proposed stability chart and how it might be used. Two sites on the volcano were chosen because of their suspected potential for failure and the impact of such a failure on cities and towns located downstream. See Figure 2.2 for approximate location of the profiles used, distinguished as Grieta and Baila Huevo. Both of the selected sites were visited during field work to verify the assumptions used in the model. A representative cross section profile through each area was developed for slope stability analysis in Slide. Figure 2.10 shows the profiles used for each analysis. 
Because the model was sensitive to groundwater table location, each profile was analyzed with three initial groundwater table depths: $15 \mathrm{~m}, 12.5 \mathrm{~m}$ and $10 \mathrm{~m}$. The results from the back analysis of the 2009 Hurricane Ida events provided a starting point for the analyses. Based on these results, a $15 \mathrm{~m}$ depth was used as a starting point. That depth was decreased incrementally up to $10 \mathrm{~m}$ to gauge the effects of a higher initial groundwater table because of previous precipitation events. For each of the three initial groundwater table depths modeled, fourteen precipitation events were used in the transient groundwater analysis. These events included the modified versions of Hurricanes Ida and Adrian, including storms that were both plus and minus $10 \%, 20 \%$ and $30 \%$ of the initial design storms. The transient analysis calculated the minimum Bishop simplified FOS at 2 hour increments for each of the fourteen rainfall events at all three initial water tables for both sites. This temporal resolution provided insight into the variation of FOS over time with cumulative rainfall, and using the two overall different storm types, showed the effects of rainfall rate on FOS. The results of this analysis provided the information to create a stability chart based on initial groundwater table depth and the expected cumulative rainfall.

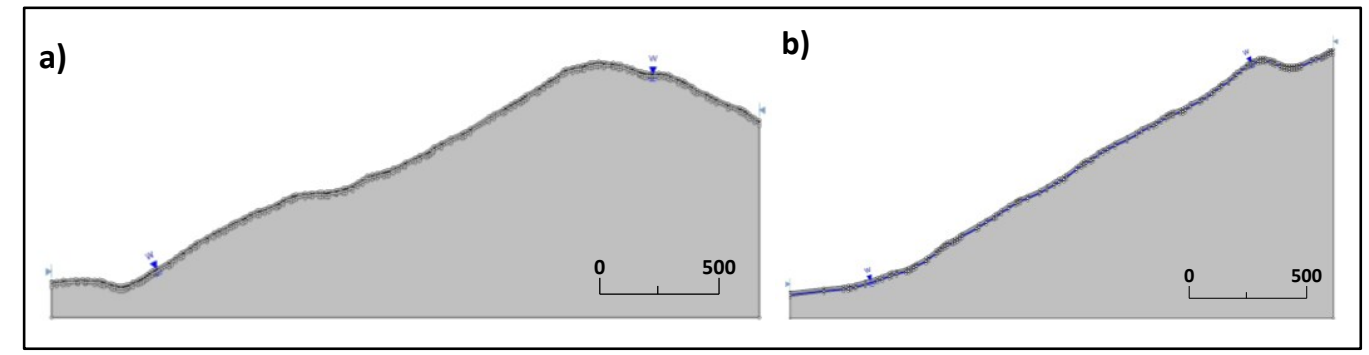

Figure 2.10: Profiles used for modeling slope stability. Profile 'a' is for Grieta cross section and profile ' $b$ ' is for Baila Huevo cross section. Scale is in meters

\subsection{Results of Forward Modeling}

The forward modeling of both cross sections affirmed the results and assumptions of the back analysis as well as provided sufficient data for the creation of stability charts for monitoring landslide potential. When modeled under the same circumstances that simulated an existing failure in the back analysis, neither profile (i.e. Grieta or Baila Huevo) produced any FOS that would indicate a likely failure (Table 2.4). With an initial water table depth of $15 \mathrm{~m}$, as suggested by the back analysis, both profiles used for the analysis appeared to be able to withstand significant rainfall from either storm type. The lowest FOS from the design Hurricanes Ida and Adrian are shown in Table 2.4. The lowest values for Ida occurred at a time of 10 hours, and for Adrian the low values occurred at time 14 hours. These minimum values are correlated with the peak rainfall amounts for each storm type. The values in all four cases are sufficiently high to suggest that the slopes would have remained stable during these rainfall events. Since both 
locations modeled experienced neither landslides nor debris flows during these actual events, the results provided further justification for the initial assumed water table depth at $15 \mathrm{~m}$.

Table 2.4: Minimum Bishop Simplified FOS using precipitation data from Hurricanes Ida and Adrian at forward model cross sections

\begin{tabular}{rcc} 
& Ida & Adrian \\
\hline Grieta & 1.394 & 1.442 \\
Baila Huevo & 1.265 & 1.325 \\
\hline
\end{tabular}

These results, as well as the other results from all model runs, were tabulated for the creation of stability charts. From the forward modeling results, it is apparent that the location of the groundwater table is critical for the stability of the slopes in San Vicente needs to be monitored. Currently there is no program of monitoring groundwater depths in this region. While these model results can be used as a baseline for disaster mitigation, the model would benefit greatly from calibration based on actual groundwater table measurements. A regular program of groundwater monitoring would provide helpful insight into actual groundwater conditions at any time. When preparing for a major rainstorm, it would be of great benefit to local agencies monitoring and making evacuation decisions to know what the current groundwater conditions were. This information could be paired with real-time rainfall measurements, in order to assess the potential landslide hazard in any given event.

\subsubsection{Stability Curve Development}

Currently the agencies that monitor storm events have real-time rainfall estimate capability. These estimates are from communication via radio with individuals working high on the volcano in coffee plantations. The reports given by these individuals are examined and particular attention is given to the reported rainfall rates experienced. The current rainfall threshold used, rainfall intensities exceeding $55 \mathrm{~mm} / \mathrm{hr}$, is based off of sparse past event data and is somewhat arbitrary. Monitoring agencies are aware of this threshold, but are still largely unaware of what to do exactly when they experience rainfall intensities of this magnitude. The addition of some form of stability chart that takes into account not only rainfall intensities, but groundwater behavior and slope failure criteria as well, would be of great benefit and additional assistance during such an event. These charts would give one more frame of reference and monitoring tool, one rooted in analyzing the actual slope failure process that leads to destructive debris flows. 
A stability chart was developed using the results from each profile. The most important factors in the analysis were determined to be initial water table depth, rainfall rate and cumulative rainfall. The initial water table depth was found using back analysis of an existing landslide, and modeled for multiple scenarios. Rainfall rate was accounted for by modeling the transient changes in FOS of known slopes during two distinct storm types with varying rainfall intensities. These storm types accounted for high intensities as well as longer times of mid intensities. Cumulative rainfall was kept independent and constrained based on past rain events. Taking into account the interrelated effects on slope stability of rainfall amount, groundwater location and rainfall rate, it was possible to develop an example stability chart. This chart gauges slope stability relatively, using an estimated FOS provided from modeling in Slide

Figure 2.11a shows the results of modeling at the Grieta location and Figure 2.11b shows the results from Baila Huevo. These locations are both on the northern slopes of the volcano and are in areas with similar slope angles. The results include each designed rainfall, displayed as a curve fitted through the FOS values for each cumulative rainfall. In both graphs, the three groups of curves each represent a different initial water table elevation, and the lines within each grouping represent the different rainfall events modeled. As this figure shows, the various initial water table depths each have a somewhat linear trend in response to the 14 different rainfall events modeled. In each case the initial response, especially for the first $200-250 \mathrm{~mm}$ of rainfall, is strikingly similar and the results only begin to differ significantly at the higher values of total rainfall in an event. Also, it is noted that the FOS results from the Hurricane Ida model storms are consistently lower by a small amount. This difference is typically $10-12 \%$ at the highest rainfall totals, but the margin is smaller at lower rainfall amounts. The Hurricane Ida results can be distinguished by the "hook" shape at the higher rainfall amounts; this hook is attributable to a slight subsidence of the water table accompanying the abrupt decrease in rainfall rate during this storm type. Again, this difference in results is pronounced at the higher rainfall amounts. 
a)

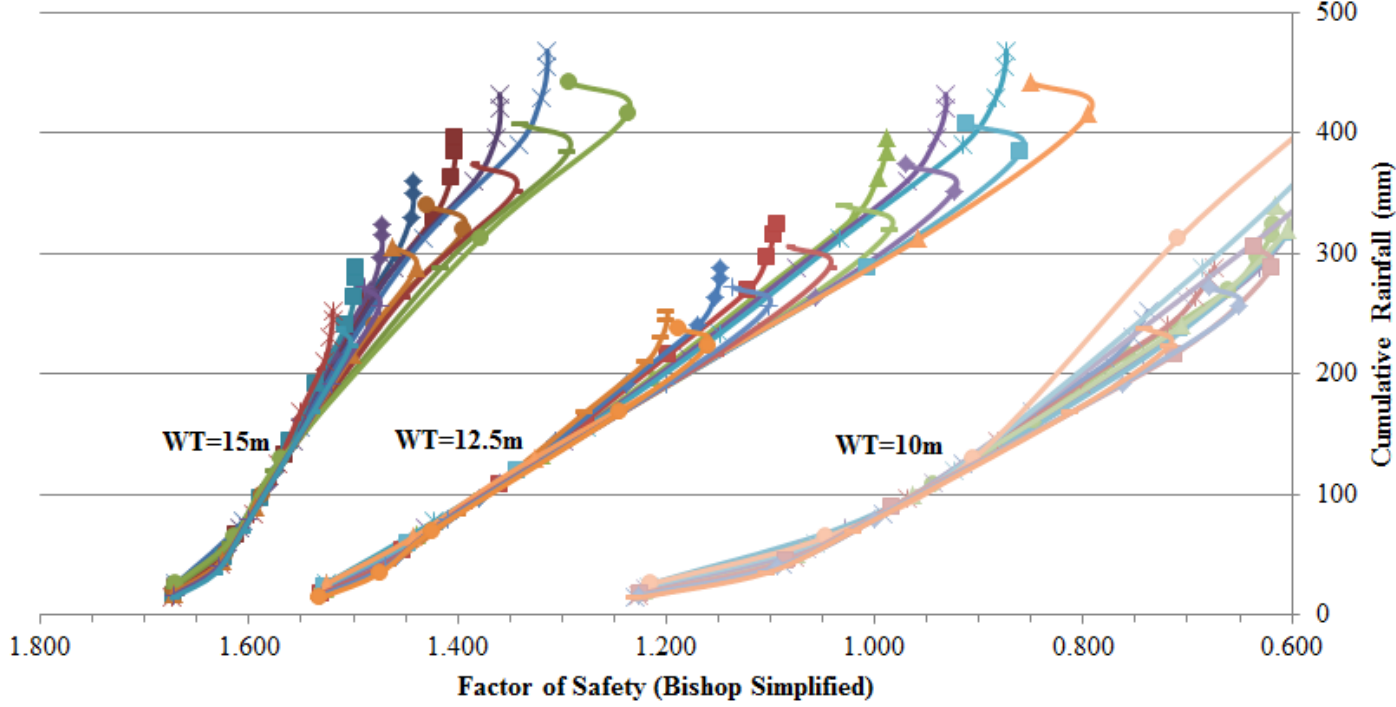

b)

Baila Huevo

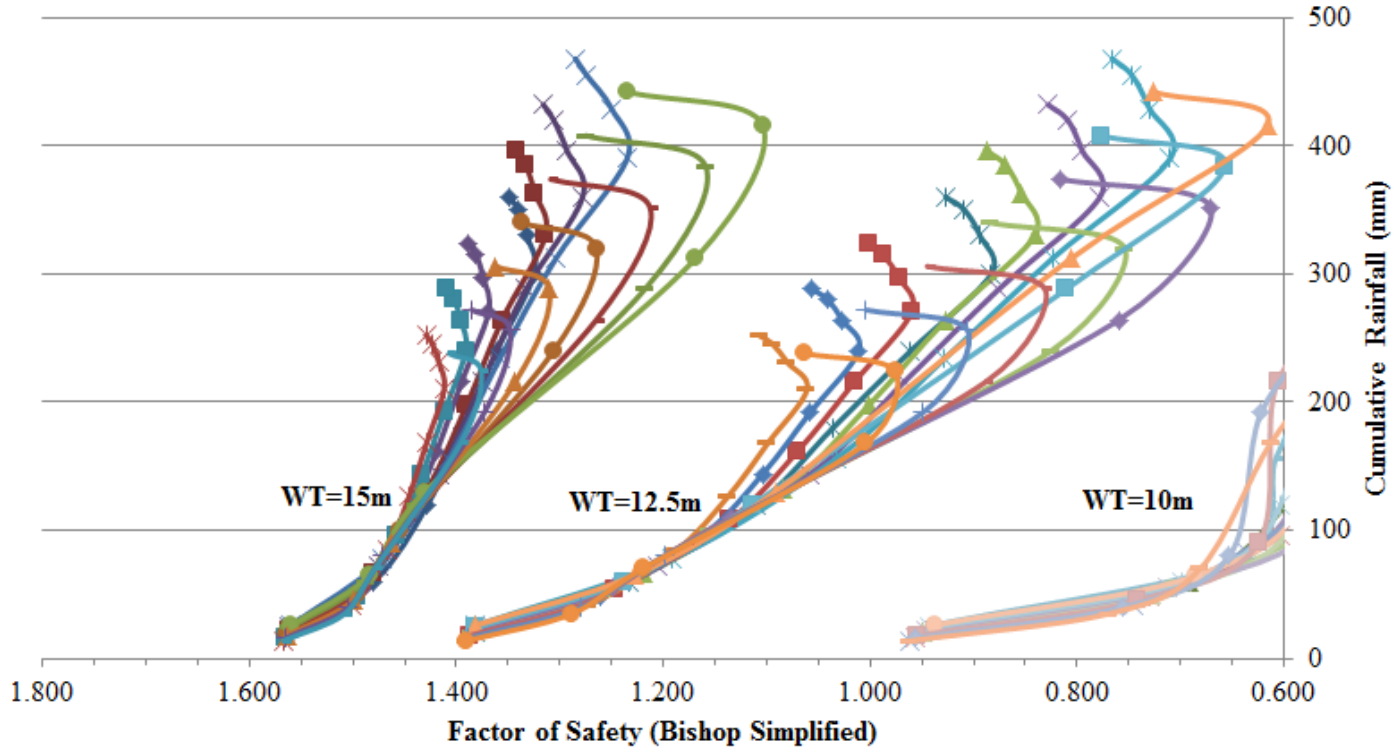

Figure 2.11: Model results for each cross section at three initial water table depths. These curves were used in the development of example stability charts.

The data contained in Figure 2.11 were then adapted into a stability chart that could be used for real time monitoring during a known extreme rainfall event (Figure 2.12). Because of the very similar response of the initial water table to the various rainfall events, it was possible to group the storms. An important consideration in the development of the stability chart was to ensure its simplicity and usability by individuals not familiar with slope stability analysis. Therefore, one of the distinct changes made 
from the initial plots seen in Figure 2.11 is the elimination of the term "FOS". The FOS values were replaced (as shown in Figure 2.12) by low, moderate, and high risk categories that are simple which can also be related to easily. The low risk zone was assigned FOS $>1.3$, moderate risk was assigned FOS of $<1.3$ and $>1.0$, and FOS $<1.0$ was assigned high risk. These values were adapted from suggestions by Hoek (2007). In other words, low risk was assigned to slopes that are considered essentially stable, moderate risk to slopes that are in transition between a stable to unstable state, and high risk to slopes that are unstable. The moderate risk zone allows accounting for the uncertainties in the model inputs.

The zones used for each water table were assigned relative rainfall intensities. These values were based on the difference between the Hurricane Ida and Hurricane Adrian results in the modeling, described above. The Ida design storm involves much higher intensities of rain for shorter period, and the FOS values in all cases are slightly lower. Thus, the low end of the zones can be said to represent a rainfall intensity close to that to be expected in Ida. Likewise, the lower intensities seen in Adrian represent the higher end of the zones. The results from Ida start off following the same general trend up to approximately $150 \mathrm{~mm}$ of rain, and then begin to break away and have lower FOS values. This trend matches precisely with the intense spike of rainfall seen in the Ida type model storms. Based on this trend, the zones associated with each initial water table act as a sort of continuum whereby results would be read off of the lower FOS side of the zone for higher rainfall intensities (such as those seen with Hurricane Ida) and off of the higher FOS side for lower intensities (like Adrian).

Three inputs would be necessary to utilize these stability charts (Figure 2.12): groundwater table depth, cumulative rainfall and approximate rainfall intensities. In other words, if the approximate groundwater depth in the area is known ahead of an intense rainfall event and the rainfall during the event was monitored in real-time, these charts could be used as guides to predict the likelihood of slope failure. The first step would be to consult the current initial depth to water table as a starting point. With this information, the individuals monitoring the storm would be able to predict the total rainfall at which slope instability is likely to be an issue. Rainfall intensity can be factored into this prediction by accounting for the example rates shown in each zone. 


\section{Example Stability Chart for Grieta Area}

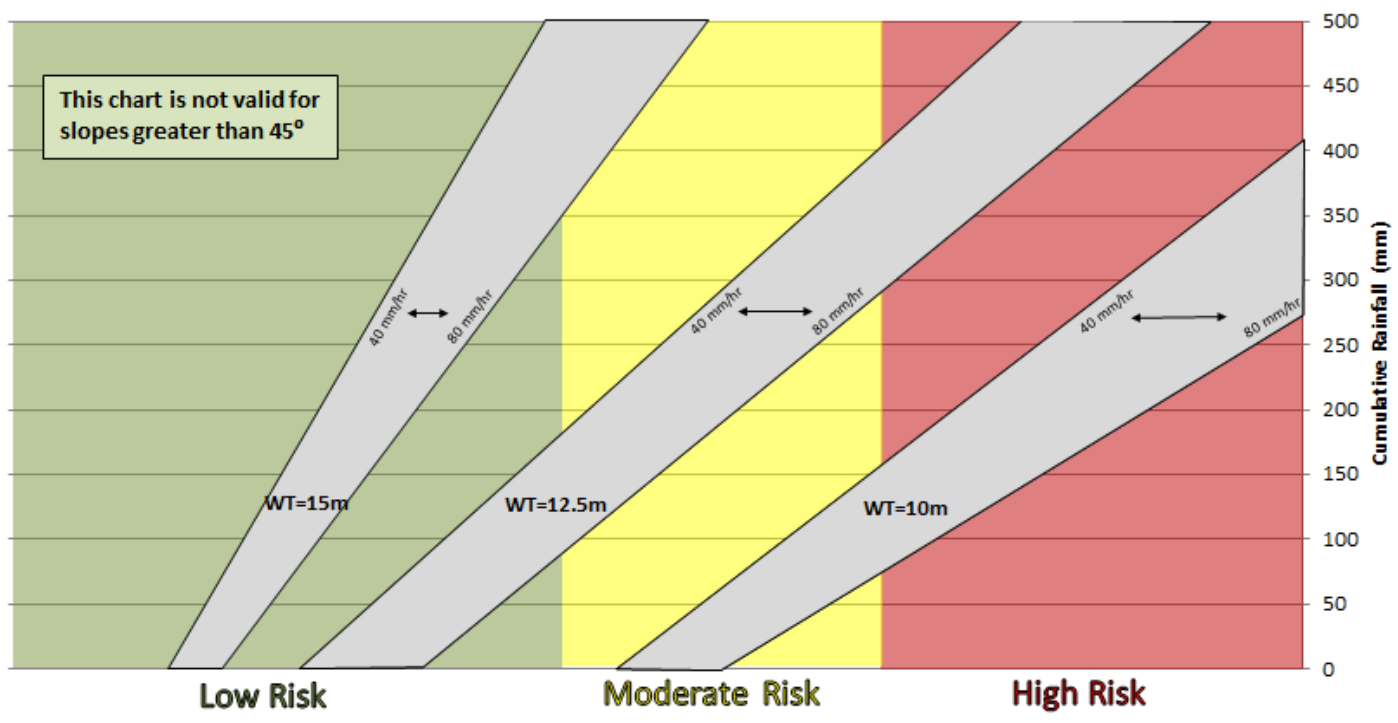

\section{Example Stability Chart for Baila Huevo Area}

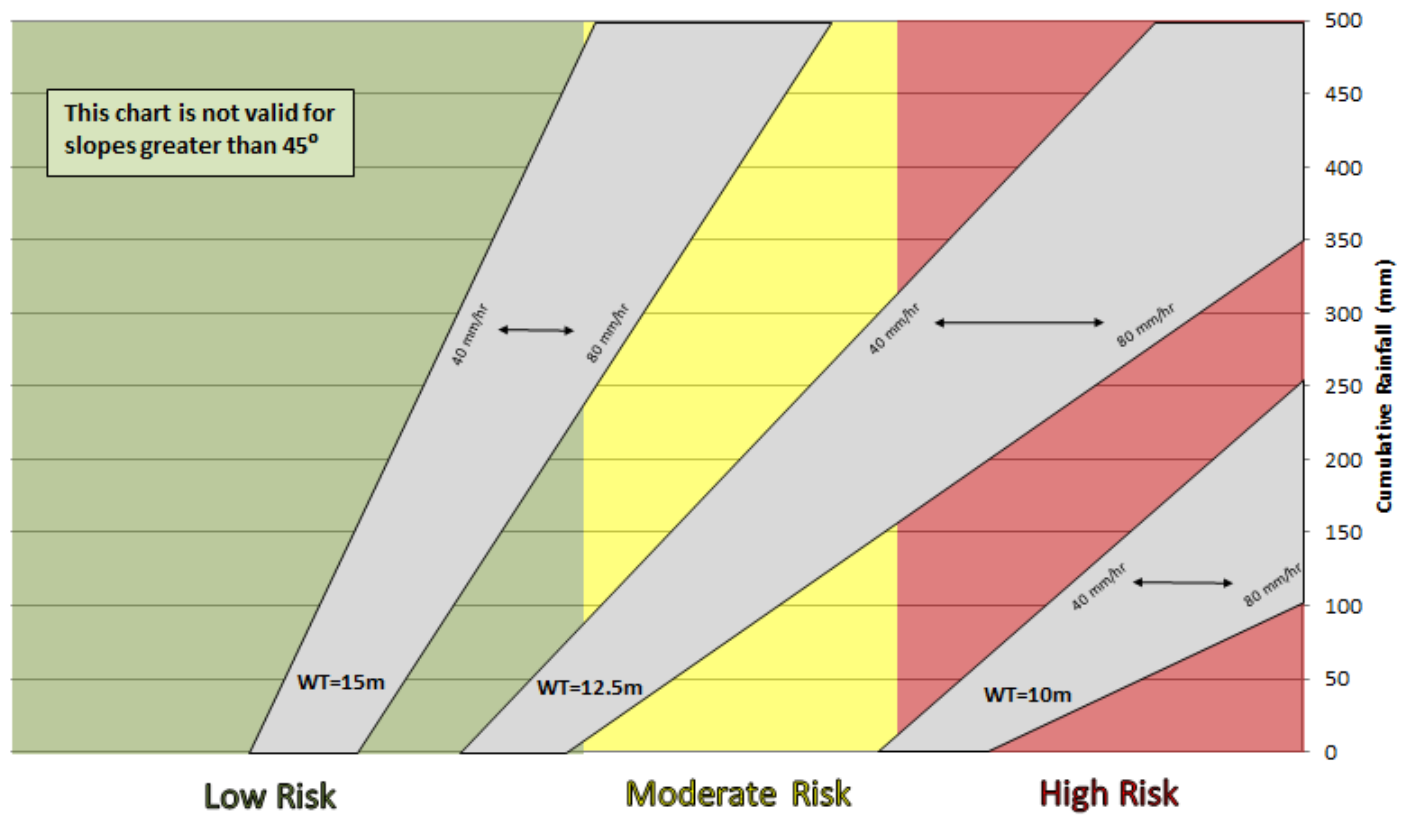

Figure 2.12: Example stability charts for Grieta and Baila Huevo locations, as they might appear for use by decision makers during an event. The similarity of the results from both profiles suggests that a combined chart could be created with both areas for use as a general reference for the northern slopes of the volcano. 


\subsubsection{Potential Impact for Communities}

As was mentioned, the areas analyzed for the creation of these example charts were chosen because of the existence of apparent tension cracks high on the volcano. These cracks are a cause of concern for many of the local monitoring agencies. It is feared that they are the sign of an imminent slope failure and debris flow during the next extreme rainfall event like Hurricane Ida or Adrian. A landslide-initiated debris flow in either of these locations would certainly affect the communities of Tepetitán and San Vicente, as well as potentially Verapaz. This analysis was undertaken to create simple charts that would benefit individuals monitoring storms and give them more information to factor into decisions to evacuate. The similarity of both charts suggests the possibility of combining the charts. A combined chart that uses both sets of curves and generalizes for all similar slopes in a region could be used in future application to represent the slopes of a region, for example north slopes of San Vicente volcano.

An example (using Figure 2.12a) of how these charts could be used by civil protection or local leaders when monitoring a rainfall event: Suppose that the groundwater depth was recently measured at 12.5 meters as part of the regular monitoring efforts. Additionally, a known tropical storm is making its way towards El Salvador. This storm is expected to bring heavy rains over one to two days and believed to be capable of dumping several hundred millimeters of rain in less than 24 hours, similar to Hurricanes Ida or Adrian. By analyzing the chart and using the zone for initial water table of $12.5 \mathrm{~m}$, one could clearly see that in a storm containing high rainfall intensities $(80 \mathrm{~mm} / \mathrm{hr})$ rainfall totals of even 150 or $200 \mathrm{~mm}$ would be enough to be considered "Moderate Risk" and therefore be on alert for potential slope failures. Real-time hourly monitoring on the volcano (as it is currently done) would result in readings regularly reported to local agencies in charge of disaster planning and evacuation. With these reports, the decision makers would know ahead of time that total rainfalls approaching $300 \mathrm{~mm}$ would be of concern. Thus, if these levels of rainfall were experienced or expected to occur, they could begin preparing to evacuate.

Current monitoring efforts, though effective, could benefit from the addition of the information that can be analyzed with this tool. This method not only takes into account the local groundwater conditions at the time of rainfall, but also attaches the method of using rainfall intensity as a threshold to the overall precipitation experienced during an event. If local Civil Protection offices were given this information and basic training about how to analyze and interpret the charts, they could prove an extremely useful tool.

\subsubsection{Recommendations for Future Work}

Certainly the biggest assumption that goes into using charts of this type is that the individual using them would need to know the approximate groundwater table depth prior to a storm event in order to properly assess the hazard posed by rainfall. This would 
necessitate a regular groundwater monitoring program, along with the equipment and expertise to accompany it. Recommendations have already been made to agencies in the San Vicente area that this be pursued, and the installation of groundwater monitoring wells and equipment in locations higher on the volcano is in the works. With the addition of this one critical piece of information, stability charts like these could be used with all the other currently available information.

In addition, the creation of the stability charts presented in this work involved a great number of simplifying assumptions. These assumptions, as outlined earlier, were conservative and, when compounded, very likely lead to overly conservative results. However, in this case they are based on the best available information and no alterations or model complications were used where there was no direct evidence to justify doing so. The assumptions used in this application that would be most likely to affect the results are constant rainfall amounts across the entire profile, constant depth to water table along the entire profile and constant soil thickness for the entire profile. These model simplifications likely lead to conservative results, but there is also the possibility that assumed material properties could affect the results either way. Again, properties used for this example were based only on available information and several key parameters were based on literature values.

A very critical assumption in our model is that the soil is cohesionless. There was much evidence of this during field testing and it was supported by a literature review. The difficulty of obtaining and transporting intact samples from such remote field sites makes it difficult to disprove this. Obtaining more accurate cohesion values would allow for more precise calibration of the model. However, if simple material properties like cohesion or a better measurement of SWCC were available, it would add much more confidence to this model. Another area where the model could be improved is factoring antecedent moisture conditions into the analysis. Several studies have shown that it is a key component in slope stability, though it is difficult to account for and accurately predict without good monitoring capabilities and equipment (Godt et al. 2009; Rahardjo et al. 2007, 2010; Rahimi et al. 2011). The effects of antecedent moisture on the stability of the slopes are very evident when examining the difference between Hurricane Adrian and Ida. Adrian occurred in May, when the soil would have very low moisture content at the start of the wet season, while Ida occurred in November, at the end of the wet season when the soil has as high moisture content as it is likely to have. Using the approach outlined in this paper, stability charts of similar fashion could be created and calibrated by accounting for these factors as best as possible. 


\subsection{Conclusion}

Back analysis of shallow rainfall-induced landslides that occurred during Hurricane Ida led to the determination of several thresholds for slope instability at San Vicente volcano. Groundwater table depth was found to have the highest effect on potential slope instability. Other potential critical factors leading to instability are cumulative rainfall and rainfall intensities. Using the results from this back analysis and field work, a slope stability model was created for analyzing the potential effects of various rainfall amounts and intensities on slope stability. The results of this iterative modeling were used to create stability charts that can be used as a tool for real-time monitoring efforts during an extreme rainfall event. These charts could cue decision makers into critical rainfall amounts or intensities where evacuation would be warranted. The framework for the development of these stability charts is outlined and recommendations for future improvements to the existing model are given. It is believed that this method could be improved and applied elsewhere for similar purposes to assist in hazard monitoring in areas where shallow landslides and the resulting debris flows pose a threat to populations. 


\subsection{Summary}

Rainfall induced shallow landslides continue to plague numerous areas around the globe and much research is directed at analyzing causes of failure and failure mechanisms (Anderson and Sitar 1995; Cascini et al. 2010; Collins and Znidarcic 2004; Crosta and Frattini 2008; Frattini et al. 2004; Montrasio et al. 2011; Ng and Shi 1998). Debris flows resulting from shallow landslides in volcanic terrains lead to numerous deaths and much destruction of property worldwide and are a critical concern when planning for disaster prevention and mitigation. The country of El Salvador is highly vulnerable to these events and has experienced astonishing losses from them (GFDRR 2011). One of the ways that the loss of life can be avoided during a landslide or debris flow is the proper evacuation of an area exposed to danger. Knowing when to evacuate is critical, and decisions are based on real time monitoring as well as past occurrences. The individuals making these decisions would benefit from practical tools.

By back analyzing the slope failure resulting from Hurricane Ida in 2009, a working model of the northern slopes of San Vicente volcano was created. Simulating the existing failure under known conditions enabled constraining the unknown inputs for the slope stability analysis. Groundwater table depth was found to have the highest effect on potential slope instability. Other potential critical factors leading to instability were cumulative rainfall and rainfall intensities. Potential future landslide initiation sites were modeled using the best information available from field work, laboratory testing and back analysis. The results of these models facilitated the development of a new method of preparing for rainfall-induced landslides in that area. This method builds upon the existing criteria used during rainfall events, and allows for factoring cumulative rainfall and groundwater conditions into the decision making process.

Forward model runs were performed to evaluate the response of each area to rainfall under different initial groundwater conditions. The model accounted for different rainfall distributions, cumulative rainfall and varying rainfall intensities, These results were then used to create stability charts that take into account all of those variables. These charts can be used before and during extreme rainfall events to know when the likelihood of a slope failure is highest. By implementing a regular groundwater monitoring program, these charts could be used to assess the likelihood of landslides and slope instability during rainfall events.

This methodology is a new approach toward preparation and real-time monitoring strategies. Current methods involve using rainfall thresholds and empirically created models that are not rooted in the physical processes that lead to slope failure. While these methods do work and are often effective in other applications and regions, they have limitations. Their application on the San Vicente volcano is limited due to lack of sufficient inventory of events to predict future failures. The method outlined in this study utilizes stability analyses that are based on the physical processes that initiate landslides. 
This ensures that even without a detailed database of past events, one can estimate potential future behavior if material properties are known. This behavior can then be translated into usable tools, such as the stability charts outlined in this research. These tools take the existing monitoring framework, namely the current, near real-time monitoring of rainfall, and augment it with further criteria that affect slope stability. The end product of this combination is a tool that can be used to make better informed decisions about what to do in the face of an extreme rainfall event.

Further improvements can be made to the method outlined in this research. There are numerous assumptions that went into the creation of this example. Potential improvements to the modeling technique would be obtained through actual measurements of groundwater depth, varying the precipitation across a profile and depth of the soil profiles as well as more direct testing of material properties. These improvements could all be factored into creating a future model of this type for San Vicente volcano or elsewhere. Also, different variables that affect slope stability could be accounted for, such as antecedent moisture conditions. Even with the assumptions that have been factored into the existing model, it still would provide beneficial insight when monitoring for a potential disaster. 


\subsection{References}

Anderson, S., and Sitar, N. (1995). "Analysis of Rainfall-Induced Debris Flows.” Journal of Geotechnical Engineering, 121(7), 544-552.

Bommer, J. J., and Rodriguez, C. E. (2002). "Earthquake-induced landslides in Central America." Engineering Geology, 63, 189-220.

Cascini, L., Cuomo, S., Pastor, M., and Sorbino, G. (2010). "Modeling of RainfallInduced Shallow Landslides of the Flow-Type." Journal of Geotechnical and Geoenvironmental Engineering, 136(January), 85-98.

Chin, K. B., Leong, E. C., and Rahardjo, H. (2010). "A simplified method to estimate the soil-water characteristic curve." Canadian Geotechnical Journal, 47(12), 13821400 .

Collins, B. D., and Znidarcic, D. (2004). "Stability Analyses of Rainfall Induced Landslides." Journal of Geotechnical and Geoenvironmental Engineering, 130(April), 362-372.

Crone, A. J., Baum, R. L., Lidke, D. J., Sather, D. N. D., Bradley, L., and Tarr, A. C. (2001). "Landslides Induced by Hurricane Mitch in El Salvador - An Inventory and Descriptions of Selected Features." USGS Open-File Report, 01-444.

Crosta, G. B., and Frattini, P. (2008). "Rainfall-induced landslides and debris flows." Hydrological Processes, 22(October 2007), 473-477.

Dilley, M., Chen, R. S., Deichmann, U., Lerner-Lam, A. L., Arnold, M., Agwe, J., Buys, P., Kjekstad, O., Lyon, B., and Yetman, G. (2005). Natural Disaster Hotspots: A Global Risk Analysis. The World Bank Hazard Management Unit, Washington, DC, 132.

Frattini, P., Crosta, G. B., Fusi, N., and Dal Negro, P. (2004). "Shallow landslides in pyroclastic soils: a distributed modelling approach for hazard assessment."

Engineering Geology, 73(3-4), 277-295.

Fredlund, D. G., and Xing, A. (1994). "Equations for the soil-water characteristic curve." Canadian Geotechnical Journal, 31(3), 521-532.

Gabet, E. J., and Mudd, S. M. (2006). "The mobilization of debris flows from shallow landslides." Geomorphology, 74(1-4), 207-218. 
GFDRR. (2011). Disaster Risk Management in Central America : GFDRR Country Notes El Salvador. 20.

Godt, J. W., Baum, R. L., and Lu, N. (2009). "Landsliding in partially saturated materials." Geophysical Research Letters, 36(2), 1-5.

Godt, J. W., Baum, R. L., Savage, W. Z., Salciarini, D., Schulz, W. H., and Harp, E. L. (2008). "Transient deterministic shallow landslide modeling: Requirements for susceptibility and hazard assessments in a GIS framework." Engineering Geology, Elsevier B.V., 102(3-4), 214-226.

Gofar, N., Lee, L. M., and Asof, M. (2006). "Transient Seepage and Slope Stability Analysis for Rainfall-Induced Landslide: A Case Study." Malaysian Journal of Civil Engineering, 18(1), 1-13.

Harp, E. L., Reid, M. E., McKenna, J. P., and Michael, J. A. (2009). “Mapping of hazard from rainfall-triggered landslides in developing countries: Examples from Honduras and Micronesia." Engineering Geology, Elsevier B.V., 104(3-4), 295-311.

Hoek, E. (2007). Practical Rock Engineering.

Hungr, O., Salgado, F. M., and Byrne, P. M. (1989). "Evaluation of a three-dimensional method of slope stability analysis." Canadian Geotechnical Journal, 26, 679-686.

Jibson, R. W., Crone, A. J., Harp, E. L., Baum, R. L., Major, J. J., Pullinger, C. R., Escobar, C. D., Martinez, M., and Smith, M. E. (2004). "Landslides triggered by the 2001 earthquakes in El Salvador." Geological Society of America Special Publications, 375, 69-88.

Kruse, S. E. (2011). “Unpublished geophysical testing results.” Personal Communication.

Larsen, M. C., and Simon, A. (1993). "A rainfall intensity-duration threshold for lanslides in a humid-tropical environment, Puerto Rico." Geografiska Annaler, $75(1), 13-23$.

Major, J. J., Schilling, S. P., Pullinger, C. R., and Escobar, C. D. (2004). "Debris Flow Hazards at San Salvador, San Vicente, and San Miguel volcanoes, El Salvador." Geological Society of America, Special Pa, 89-108.

Major, J. J., Schilling, S. P., Pullinger, C. R., Escobar, C. D., and Howell, M. M. (2001). "Volcano-Hazard Zonation for San Vicente Volcano, El Salvador." USGS OpenFile Report, 01-367, 1-22. 
Montgomery, D. R., Sullivan, K., and Greenberg, H. M. (1998). "Regional test of a model for shallow landsliding." Hydrological Processes, 955(November 1997).

Montrasio, L., Valentino, R., and Losi, G. L. (2011). “Towards a real-time susceptibility assessment of rainfall-induced shallow landslides on a regional scale." Natural Hazards and Earth System Science, 11(7), 1927-1947.

Ng, C. W. W., and Shi, Q. (1998). "Influence of rainfall intensity and duration on slope stability in unsaturated soils." Quarterly Journal of Engineering Geology, 31(May), $105-113$.

Del Potro, R., and Hürlimann, M. (2008). "Geotechnical classification and characterisation of materials for stability analyses of large volcanic slopes." Engineering Geology, 98(1-2), 1-17.

Rahardjo, H., Nio, A. S., Leong, E. C., and Song, N. Y. (2010). "Effects of Groundwater Table Position and Soil Properties on Stability of Slope during Rainfall." Journal of Geotechnical and Geoenvironmental Engineering, 136(November), 1555-1564.

Rahardjo, H., Ong, T. H., Rezaur, R. B., and Leong, E. C. (2007). "Factors Controlling Instability of Homogeneous Soil Slopes under Rainfall." Journal of Geotechnical and Geoenvironmental Engineering, 133(December), 1532-1543.

Rahimi, A., Rahardjo, H., and Leong, E. C. (2011). "Effect of Antecedent Rainfall Patterns on Rainfall-Induced Slope Failure." Journal of Geotechnical and Geoenvironmental Engineering, 137(May), 483-491.

Rocscience. (2011). “Slide 6.011.” Toronto, ON.

Rolo, R., Bommer, J. J., Houghton, B. F., Vallance, J. W., Berdousis, P., Mavrommati, C., and Murphy, W. (2004). "Geologic and engineering characterization of Tierra Blanca pyroclastic ash deposits." Geological Society of America, Special Pa, 55-67.

Rose, W. I., Bommer, J. J., and Sandoval, C. (2004). "Natural hazards and risk mitigation in El Salvador : An introduction." Geological Society of America, Special Pa, 1-4.

Rotolo, S. G., Aiuppa, A., Pullinger, C. R., and Parello, F. (1998). "An introduction to San Vicente (Chichontepec) Volcano, El Salvador." Revista Geologica de America Central, 21, 25-36.

Schweig, E. S., Major, J. J., and Godt, J. W. (2010). Reconnaissance Survey of Landslide Hazards at Volcán de San Salvador and Volcán de San Vicente, El Salvador, and evaluation of Servicio Nacional de Estudios Territoriales (SNET) operational capacity and capability. Most, 1-9. 
Scott, K. M., Vallance, J. W., Kerle, N., Luis Macias, J., Strauch, W., and Devoli, G. (2005). "Catastrophic precipitation-triggered lahar at Casita volcano, Nicaragua: occurrence, bulking and transformation." Earth Surface Processes and Landforms, 30(1), 59-79.

SNET. (2011). "Unpublished rainfall data from San Vicente, El Salvador.”

Takahashi, T. (1981). "Debris Flows.” Annual Review of Fluid Mechanics, 13, 57-77.

Tutluoglu, L., Ferid Öge, I., and Karpuz, C. (2011). “Two and three dimensional analysis of a slope failure in a lignite mine." Computers \& Geosciences, 37(2), 232-240.

Varnes, D. J. (1978). “Slope Movement Types and Processes.” Transportation Research Board Special Report: Landslides: Analysis and Control, 176, 11-33. 
5.0 Appendices 


\subsection{Appendix A: Field Work Report and Results of Field Tests}

\section{Report of Field Work Completed on the San Vicente Volcano, EI Salvador May 14-23, 2012}

\section{Dan Smith}

\section{Introduction}

Located in a tectonically active zone along the "Ring of Fire" on the Pacific coast of Central America, El Salvador is a country that is regularly affected by natural disasters. The most apparent threat to a large percentage of the population of El Salvador is the central volcanic chain, located approximately $35 \mathrm{~km}$ from the coast and $170 \mathrm{~km}$ from the Middle America Trench. The San Vicente (San Vicente) Volcano in central El Salvador has a recurring and destructive pattern of landslides and lahars (volcanic debris flows) occurring on the northern slopes of the volcano. The cause of these events is thought to be a combination of very steep slopes, low-strength material properties, and occasional extreme rainfall events associated with the tropical rainy season. Limited previous studies have been done and little information exists regarding the stability of these slopes. A field campaign was conducted in May 2012 to gather samples from known landslide zones and suspected future hazard areas, as well as perform in situ permeameter and shear vane tests to test the infiltration capacity and shear strength of the materials on the volcano. This information will be used to create a model of the slopes to better understand potential hazard zones for future landslides on the volcano.

\section{Objectives}

The objectives of the field campaign were to:

1) Observe firsthand the conditions and materials located high up on the volcano in the active slide zones and potential future zones

2) Gather samples of these materials in various locations to bring back for lab testing

3) Perform field tests where appropriate to better quantify the natural behavior of the materials in a non-laboratory setting

Completion of these objectives allowed for a properly constructed model of the slopes that can be used to identify proximal hazard zones surrounding potential landslide areas. 


\section{Methods}

Work performed during this field campaign included field permeameter tests, vane shear tests and sample gathering. These methods were believed to provide the most applicable insight into the material properties needed to create the best model possible, while still being easily performed in diverse, remote and often nearly inaccessible situations.

The permeameter used was a constant head borehole permeameter that functioned using a reservoir of water to keep a steady water level in a shallow borehole near the surface. This method of infiltration testing uses the theory of a saturated "bulb" of water surrounding the borehole to determine a steady-state infiltration rate for a given soil and allows the user to access the material below the surface without being excessively invasive. The permeameter functions by filling the reservoir with water and then inverting it into a pre-made borehole and recording the drop in water level over time, stopping when it reaches a steady rate. It functions by much the same theory as a standard office water cooler, with a small hole in the side to keep the water level steady during the test. During testing, as water slowly infiltrates into the soil the water level will drop below the hole, allowing a small amount of air into the reservoir and displacing an equal amount of water, which will refill the hole back to its original head level. Using the steady state flow rate out of the permeameter, a few simple calculations can be performed to obtain the infiltration rate for that particular area.

The vane shear test is a common field test for finding the approximate shear strength of a material. This test is simple and gives a good idea of in situ shear strengths of cohesive materials. The test is performed using a "vane" that is pushed into the soil carefully to avoid disturbing the area, and then rotated with a device capable of measuring the amount of torque applied to the vane before the material surrounding it fails. For this field campaign, a torque wrench capable of $250 \mathrm{ft}-1 \mathrm{bs}$ was used. While testing, the user applies torque to the vane until the material fails and the vane slips and begins to rotate in the soil. Using the peak torque applied to the vane and the dimensions of the vane itself to calculate the area of shear surface, the shear strength can be calculated.

Samples were gathered where appropriate to bring back for grain size analysis and other lab testing. At each field site where testing was performed, the various accessible soil horizons were all sampled to get a better idea of subsurface soil structure to create a more accurate model. Samples were taken on a "representative" basis, in which the weathered surface material was removed and undisturbed materials beneath representing those in the area were placed into plastic bags and labeled accordingly. 


\section{Field Sites}

Field sites were chosen based on accessibility and suspected potential for performing field tests and gathering representative samples. Seven separate areas were visited, and field testing was performed at five of these. From these sites, twelve total material samples were obtained. The shear vane device was applicable at only two of the sites because of very low apparent shear strengths, while the permeameter was used in five of the materials. Table 5.1 summarizes the locations and work performed at each site.

\section{Table 5.1: Field Work Summary}

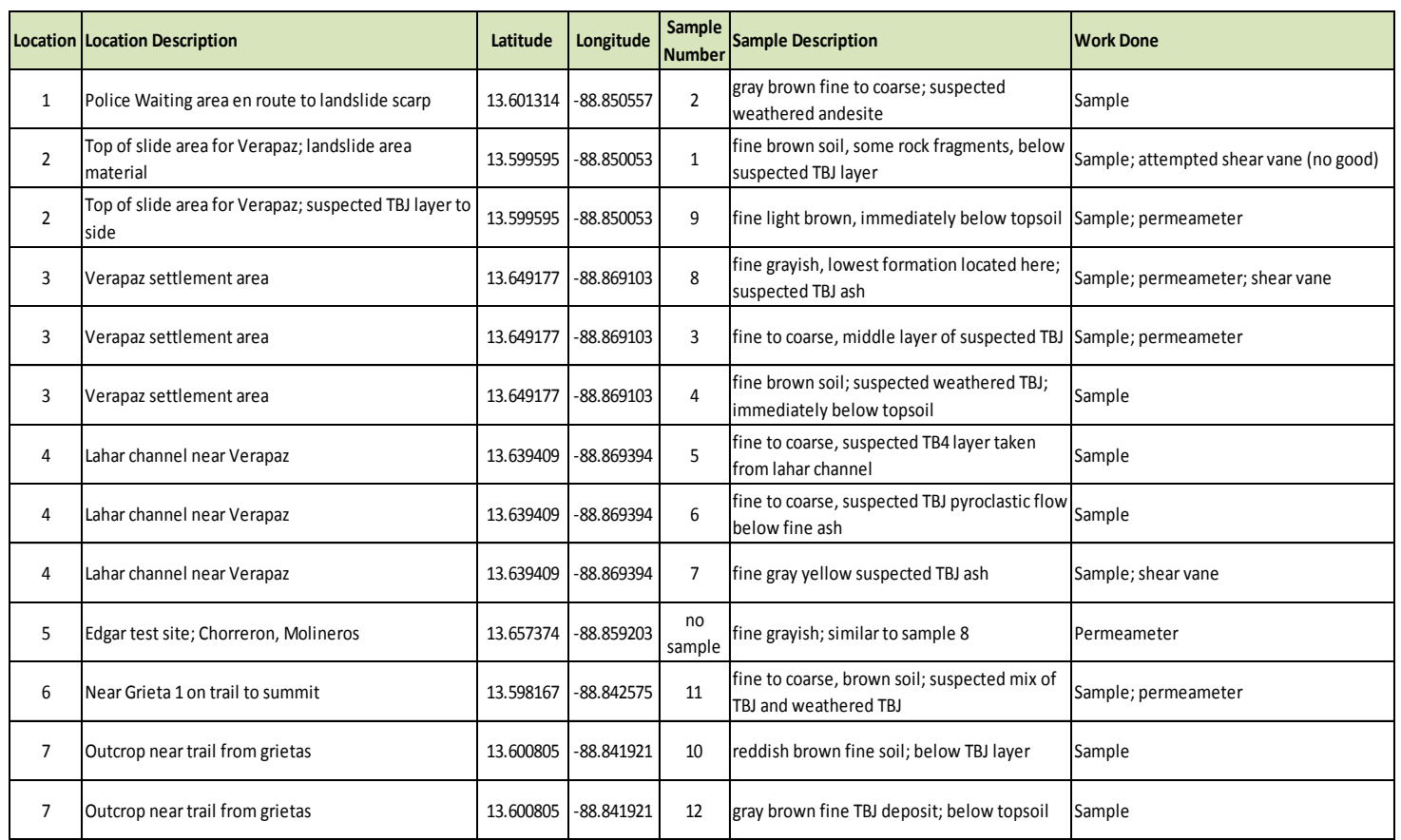

This work was completed with the assistance and cooperation of several Salvadoran counterparts, including the University of El Salvador, Civil Protection San Vicente and the Centro para Proteccion de Desastres (CEPRODE). Field excursions consisted of various teams of people ranging from three to thirty persons, depending on the accessibility of the location visited and scope of work to be performed. Specifically, Professors Edgar Antonio Orantes and Jose Fredy Cruz Centeno from the University of El Salvador provided field assistance and equipment, along with a group of students for a day spent climbing to the top of the Verapaz slide. Adonnay Hernandez, Rutilio Antonio Parada Galan and Javier Sorto from CEPRODE also provided equipment and field assistance for several site visits and Santiago Crespin and Fausto Moreno from San Vicente Civil Protection along with each community's Civil Protection representatives aided in visiting the crack area on the eastern cone of the volcano. Special thanks also to Inspector Mauricio Saade from the Policia Nacional Civil de San Vicente for providing security officers on several of the field days. 


\section{Future Work}

Now that the field testing has been performed and samples of the materials found on the volcano are available for testing, the first step will be to perform lab work on the samples. Tests to be performed include a grain size sieve analyses, as well as density and direct shear tests. The properties obtained from these tests and the field tests will be combined with field observations and existing knowledge of the structure of the volcano when constructing the model in Slide 6.011 (Rocscience, Inc., Toronto, Ontario). This model will provide a better understanding of possible future landslide triggering events, which can be further applied to prepare agencies and communities where people could be at risk in the case of an event. 


\subsection{Appendix B: Grain Size Analyses}

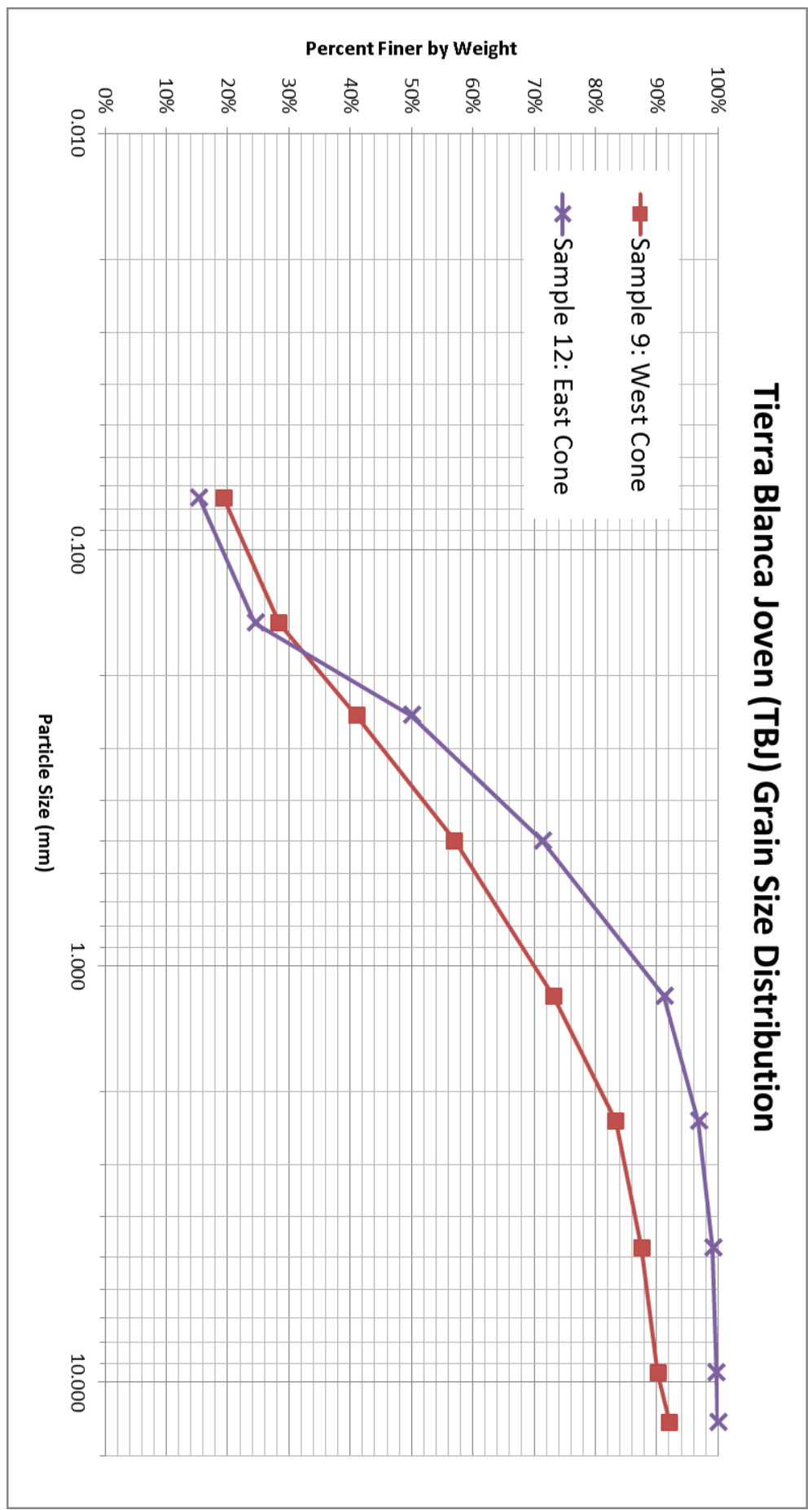

Figure 5.1: Grain Size Distribution for TBJ samples 


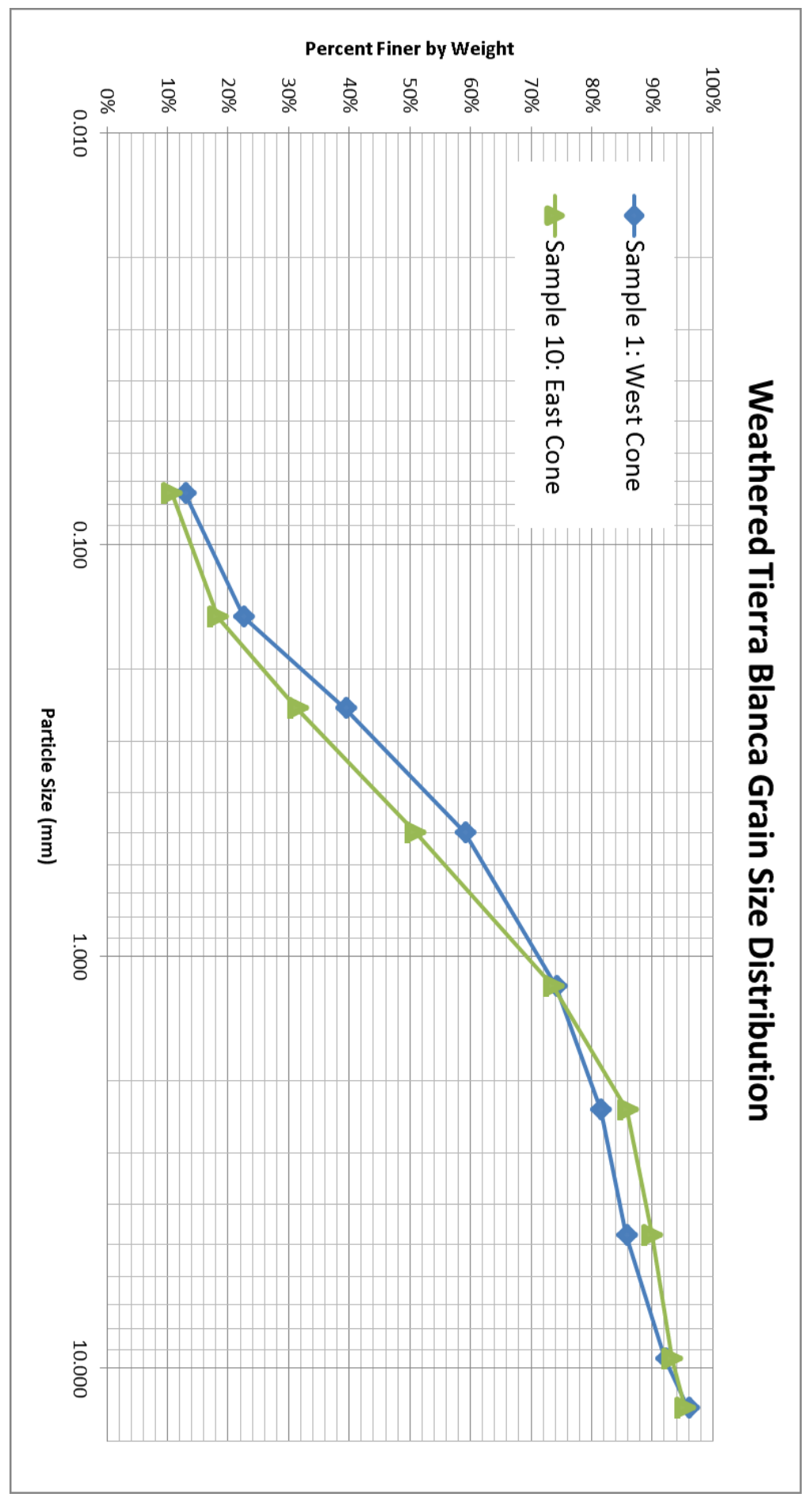

Figure 5.2: Grain Size Distribution for Weathered Volcanics samples 


\subsection{Appendix C: Supporting Calculations}

\section{Hydraulic Conductivity}

Hydraulic conductivity was testing using a simple field permeameter that uses the basic concepts of a constant head permeameter to find an in situ hydraulic conductivity. As specified by the manufacturer of the permeameter, the equation that can be used for this calculation is:

$$
K_{\text {sat }}=Q \frac{\left[\sinh ^{-1}\left(\frac{H}{r}\right)-\left\{\left(\frac{r}{H}\right)^{2}+1\right\}^{\frac{1}{2}}+\frac{r}{H}\right]}{2 \pi H^{2}}
$$

Where $\mathbf{Q}$ is the steady state flow rate out of the reservoir from testing, $\mathbf{H}$ is the height of water in the test borehole used and $\mathbf{r}$ is radius of the borehole.

For the field tests on the materials used in this model, the hydraulic conductivity of the soil would be calculated as:

$$
\begin{gathered}
K_{\text {sat }}=535,000 \frac{c c}{d} \frac{\left[\sinh ^{-1}\left(\frac{18.0 \mathrm{~cm}}{3.5 \mathrm{~cm}}\right)-\left\{\left(\frac{3.5 \mathrm{~cm}}{18.0 \mathrm{~cm}}\right)^{2}+1\right\}^{\frac{1}{2}}+\frac{3.5 \mathrm{~cm}}{18.0 \mathrm{~cm}}\right]}{2 \pi 18.0 \mathrm{~cm}^{2}} \\
K_{\text {sat }}=398.4 \frac{\mathrm{cm}}{\mathrm{d}}=4.6 \times 10^{-5} \frac{\mathrm{m}}{\mathrm{s}}
\end{gathered}
$$

The final value, $4.6 \times 10^{-5} \frac{m}{s}$ was used for the hydraulic conductivity of both of the modeled volcanic soil layers in the transient groundwater analysis. 


\section{Soil Water Characteristic Curve (SWCC)}

The Fredlund and Xing parameters for SWCC creation ( $a, m$ and $n$ ) were calculated based on a method outlined in Chin et al. (2010). This method uses the grain size analysis curve of nonplastic soils to estimate the Fredlund and Xing parameters, which the Rocscience Slide program uses to generate a SWCC for use in modeling. The equations outlined in Chin et al. are as follows (equations $5 a-5 h$ ):

$$
\begin{aligned}
& a=1.14 a_{1}-0.5 \\
& a_{1}=-2.79-14.1 \log \left(D_{20}\right)-1.9 \times 10^{-6} P_{200}^{4.34}+7 \log \left(D_{30}\right)+0.055 D_{100} \\
& D_{100}=10^{\left[4 \log \left(D_{90}\right)-\log \left(D_{60}\right)\right] / 3}
\end{aligned}
$$

$$
\begin{aligned}
& n=0.936 n_{1}-3.8 \\
& n_{1}=\left[5.39-0.29 \ln \left(P_{200} \frac{D_{90}}{D_{10}}\right)+3 D_{0}^{0.57}+0.021 P_{200}{ }^{1.19}\right]\left[\frac{30}{\log \left(D_{90}\right)-\log \left(D_{60}\right)}\right]^{0.1} \\
& D_{0}=10^{\left[3 \log \left(D_{10}\right)-\log \left(D_{30}\right)\right] / 2} \\
& m=0.26 e^{0.758 m_{1}}+1.4 D_{10} \\
& m_{1}=\log \left[\frac{20}{\log \left(D_{30}\right)-\log \left(D_{10}\right)}\right]^{1.15}-1+\frac{1}{n}
\end{aligned}
$$

Using these equations and substituting values from the grain size analyses in Appendix B as well as some gleaned from Rolo et al. (2004), this leads to the following values for $a$, $m$, and $n$ : 
TBJ

$$
\begin{aligned}
& D_{100}=10^{[4 \log (9.50)-\log (0.60)] / 3}=23.86 \\
& a_{1}=-2.79-14.1 \log (0.08)-1.9 \times 10^{-6} 19.34^{4.34}+7 \log (0.14)+0.055 \\
& * 23.86=7.40 \\
& a=1.14 * 7.40-0.5=7.93 \\
& D_{0}=10^{[3 \log (0.04)-\log (0.14)] / 2}=0.02 \\
& n_{1}=\left[5.39-0.29 \ln \left(19.34 \frac{9.50}{0.04}\right)+3 * 0.02^{0.57}+0.021\right. \\
& \left.* 19.34^{1.19}\right]\left[\frac{30}{\log (9.50)-\log (0.60)}\right]^{0.1}=5.51 \\
& n=0.936 * 5.51-3.8=1.36 \\
& m_{1}=\log \left[\frac{20}{\log (0.14)-\log (0.04)}\right]^{1.15}-1+\frac{1}{1.36}=1.41 \\
& m=0.26 e^{0.758 * 1.41}+1.4 * 0.04=0.81
\end{aligned}
$$




\section{Weathered Volcanics}

$$
\begin{aligned}
& D_{100}=10^{[4 \log (7.80)-\log (0.51)] / 3}=19.36 \\
& a_{1}=-2.79-14.1 \log (0.11)-1.9 \times 10^{-6} 12.94^{4.34}+7 \log (0.19)+0.055 \\
& * 19.36=6.64 \\
& a=1.14 * 6.64-0.5=7.06 \\
& D_{0}=10^{[3 \log (0.06)-\log (0.19)] / 2}=0.03 \\
& n_{1}=\left[5.39-0.29 \ln \left(12.94 \frac{7.80}{0.06}\right)+3 * 0.03^{0.57}+0.021\right. \\
& \left.* 12.94^{1.19}\right]\left[\frac{30}{\log (7.80)-\log (0.51)}\right]^{0.1}=5.68 \\
& n=0.936 * 5.68-3.8=1.52 \\
& m_{1}=\log \left[\frac{20}{\log (0.19)-\log (0.06)}\right]^{1.15}-1+\frac{1}{1.52}=1.38 \\
& m=0.26 e^{0.758 * 1.38}+1.4 * 0.06=0.82
\end{aligned}
$$

These values for $a, m$, and $n$ were entered into the Slide program, which then takes them and calculates an SWCC for each material and uses this curve as a part of the slope stability calculations. 